\title{
Slowness vector estimation over large-aperture sparse arrays with the Continuous Wavelet Transform (CWT): Application to Ocean Bottom Seismometers
}

Roberto Cabieces $^{1}$, Frank Krüger ${ }^{2}$, Araceli Garcia-Yeguas ${ }^{3}$, Antonio Villaseñor ${ }^{4}$, Elisa Buforn $^{5,6}$, Antonio Pazos ${ }^{1}$, Andrés Olivar-Castaño ${ }^{7}$ and Jaime Barco ${ }^{8}$.

${ }^{1}$ Royal Spanish Navy Observatory, Cecilio Pujazon s/n.E-11100.rcabdia@roa.es

${ }^{2}$ University of Potsdam, Institute of Geoscience, Karl-Liebknecht-Str. 24-25 14476 PotsdamGolm.Frank.Krueger@geo.uni-potsdam.de

${ }^{3}$ University of Granada, Campus Universitario Cartuja, s/n, 18011, Granada

${ }^{4}$ Institute of Marine Sciences, Pg. Marítim de la Barceloneta, 37-49, E-08003 Barcelona, Spain

${ }^{5}$ Universidad Complutense de Madrid, Plaza de Ciencias, 1, Ciudad Universitaria 28040 Madrid, Spain

${ }^{6}$ IGEO. Universidad Complutense de Madrid-CSIC, Madrid, Spain

${ }^{7}$ University of Oviedo, Oviedo, Spain

${ }^{8}$ Instituto Geográfico Nacional, Madrid, Spain 


\section{Summary}

This work presents a new methodology designed to estimate the slowness vector in largeaperture sparse Ocean Bottom Seismometer (OBS) arrays. The Continuous Wavelet Transform (CWT) is used to convert the original incoherent traces that span a large array, into coherent impulse functions adapted to the array aperture. Subsequently, these impulse functions are beamformed in the frequency domain to estimate the slowness vector. We compare the performance of this new method with that of an alternative solution, based on the Short-Term Average/Long-Term Average algorithm and with the method based on the trace envelope, with the ability to derive a very fast detection and slowness vector estimation of seismic signal arrivals. The new array methodology has been applied to data from an OBS deployment with an aperture of $80 \mathrm{~km}$ and an interstation-distance of about $40 \mathrm{~km}$, in the vicinity of Cape Saint Vincent (SW Iberia). A set of 17 regional earthquakes with magnitudes $2<\operatorname{mbLg}<5$, has been selected to test the capabilities of detecting and locating regional seismic events with the Cape Saint Vincent OBS Array. We have found that there is a good agreement between the epicentral locations obtained previously by direct search methods and those calculated with the CWT technique. We show that the proposed CWT method can detect seismic signals and estimate the slowness vector from regional earthquakes with high accuracy and robustness under low signalto-noise ratio conditions. Differences in epicentral distances applying direct search methods and the CWT technique are between $1 \mathrm{~km}$ and $21 \mathrm{~km}$ with an average value of $12 \mathrm{~km}$. The back-azimuth differences range from $1^{\circ}$ to $7^{\circ}$ with an average of $1.5^{\circ}$ for the $\mathrm{P}$-wave and ranging from $1^{\circ}$ to $10^{\circ}$ with an average of $3^{\circ}$ for the S-wave.

Keywords: Array, OBS, Wavelet, Beamforming, Envelope, STA/LTA. 


\section{Introduction}

Since the early 1960s ground seismic arrays have helped to disclose Earth structures in great detail (Doornbos, 1974; Goldstein et al., 1992; Krüger et al., 1993; Weber et al., 1996; Kito and Krüger, 2001), to detect and classify nuclear explosions (Carpenter, 1965; Kim and Richards, 2007; Selby, 2010; Gibbons and Ringdal, 2012; Kværna and Ringdal, 2013), to ocean microseismic analysis (Cessaro, 1994; Friedrich et al., 1998; Behr et al., 2013; Reading et al., 2014; Gal et al., 2015), and more recently to track the rupture spread of big earthquakes (Ishii et al., 2005; Krüger and Ohrnberger, 2005; Koper et al., 2011).

Arrays have shown a special ability to enhance the coherent signals over noise and to lower the signal detection threshold, owing to phase alignment and signal stacking of the sensor recordings (Rost and Thomas, 2002; Schweitzer et al., 2002; Rost and Thomas, 2009). In addition, the most recent advances in marine technology let us explore seismic activity (Grevemeyer et al., 2017) and the acoustic wavefield through Ocean Bottom Seismometers (OBSs) and pressure sensors (Collins et al., 2002; Dahm et al., 2006; Tilmann and Dahm, 2008). In this sense, the capabilities of array techniques in OBS deployments (e.g., submarine volcano exploration or earthquake location with marine foci) awaken an increased interest as well as having paramount importance in exploring the Earth's structure under the ocean bottom floor using new approaches.

However, to implement array techniques in OBS studies presents difficulties such as i) timing errors in the array sensors (Hannemann et al., 2013; Le et al., 2018), which make it impossible to apply any array techniques to accurately estimate the apparent slowness vector, ii) misorientation of the seismic sensor horizontal components (Stachnik et al., 2012; Zha et al., 2013) which are also important to improve the detection and to obtain an accurate slowness of shear S-waves and the last significant difficulty, iii) the accurate ocean floor positioning 
(Shiobara et al., 1997), commonly estimated with a positioning error on the order of several tens of meters. Additional problems arise from the array technique's implementation itself, either in the frequency domain (Capon, 1969) or time domain (Frankel et al., 1991), as it relies on high signal coherency across the array sensor records, which is generally not valid for large aperture arrays due to the degradation of the wavefront caused by heterogeneities of the structure beneath the array stations.

Ringdal et al. (1975) proposed for the first time an incoherent beamform detector, based on beamforming envelope traces instead of waveform beams and demonstrated the superiority of incoherent beamforming over conventional beamforming for regional seismic events recorded at the large aperture NORSAR array in southern Norway. Gibbons et al. (2008); (Gibbons, 2012) used a modified approach of incoherent beamforming based on extracting characteristic functions from the multitaper spectrogram and also applying it to recordings from the NORSAR array. Kao and Shan (2007) implemented the source-scanning algorithm using P-wave envelopes to identify the earthquake's rupture plane using local network data. In the following years, these ideas have been shared with migration techniques applying shift-and-stack envelopes and characteristic functions to locate seismic events (Gharti et al., 2010; Grigoli et al., 2013), see also (Krüger et al., 2020) for an application to OBS data.

This paper focuses on a new array technique to overcome the problem of dealing with incoherent and noisy waveforms in large aperture arrays, based on the Continuous Wavelet Transform (CWT) (Grossmann et al., 1989; Kumar and Foufoula-Georgiou, 1997). The wavelet analysis provides a multiresolution time-frequency signal analysis, specially designed to detect transient and non-stationary signals as is the case for seismic waves (Bear and Pavlis, 1997). Furthermore, the wavelet properties allow us to denoise the traces of the array from oceanic ambient noise and to extract transient signals that preserve the phase arrival times from the characteristics of the time-frequency energy plane (i.e., Characteristic Functions, CFs). The CFs 
will play a key role in fulfilling the coherency requirement of array techniques and will enable us to obtain the slowness vector as well as the enhancement of the oceanic phase onsets. Alternatively for comparison purposes, CFs have also been generated using the fast and reliable Short-Term Average/Long-Term Average (STA/LTA) method (Allen, 1982; Grigoli et al., 2013), and with the help of the seismic trace envelope (Ringdal et al., 1975). The high frequency Po/So guided waves observed in the OBSs usually have emergent onsets and the So is frequently obscured by the Po coda (Mallick and Frazer, 1990; Kennett and Furumura, 2013; Shito et al., 2013). However, the maxima displayed by the CFs facilitate determining with relatively high temporal resolution the oceanic Po and So wave arrivals.

The above-mentioned methods have been applied to regional data from an OBS deployment experiment carried out in the Horseshoe Abyssal Plain (HAP), SW Iberia (Fig. 1). The OBS array is placed in the HAP and it is limited in the north by the Gorringe Bank (GB), in the south by the Seine Abyssal plain (SAP) and in the east by the Gulf of Cadiz (GC). A total of 6 OBSs were deployed, forming an array with an $\sim 40 \mathrm{~km}$ inter-distance and $\sim 80 \mathrm{~km}$ aperture (Fig. 1). Unfortunately, one OBS (OBS04) was lost during the recovery operation.

\section{FIGURE 1}

The crustal structure of the study area is complex, presenting strong seismic velocity contrasts and gradients. Most interpretations of the GB consider it to be either an intruded mantle block or a block made of oceanic crust (Sallarès et al., 2013). Sallarès et al. (2013) modeled a seismic refraction and wide-angle reflection profile, and found a thick sediment layer in the HAP (up to $4-5 \mathrm{~km}$ ) with $\mathrm{P}$ wave velocities ranging from 1.5 to $3.0 \mathrm{~km} / \mathrm{s}$, and a sediment-starved GB showing much higher $\mathrm{P}$ wave velocities ranging from 5 to $7 \mathrm{~km} / \mathrm{s}$. The basement below the sediments in the HAP shows a strong vertical velocity gradient, increasing from $\sim 3.0 \mathrm{~km} / \mathrm{s}$ to $\sim 8.0 \mathrm{~km} / \mathrm{s}$ over a mere $\sim 8 \mathrm{~km}$. 
From a seismological point of view, the study area and the neighboring GC are of great interest. Several geodynamic models have been proposed to explain the seismicity of the region (Carminati et al., 1998; Gutscher et al., 2002; Platt et al., 2003), but the structures involved in the seismic activity are still a matter of debate. So far, it has not been possible to unequivocally define the presence of a convergent boundary between Eurasia and Africa (Buforn et al., 2004; Grandin et al., 2007; Pro et al., 2013). Although no structure capable of generating large earthquakes has been convincingly identified, strong earthquakes have nonetheless occurred in the area. A well-known example is the earthquake of Lisbon in 1755 (M 8.5) (Gutscher, 2004; Solares and Arroyo, 2004), which generated a tsunami that struck the coasts of Portugal, Morocco and Spain. Moreover, in the last 40 years, three earthquakes with Mw higher than 5.0 have occurred SW of Cape St. Vincent. Pro et al. (2013) found that they had similar characteristics, but different rupture geometries.

\section{Data and instruments}

Data were acquired from 5 OBSs placed $200 \mathrm{~km} \mathrm{SW}$ of Cape Saint Vincent in the deep sea in $4 \mathrm{~km}$ water depth, operating for 8 months (September 2015 - April 2016). The array has an aperture of $80 \mathrm{~km}$ and a minimum inter-sensor distance of $40 \mathrm{~km}$ (Fig. 1). OBS 01, 02, and 03 were equipped with a three-component broadband seismometer of type Güralp CMG-40T, with a flat response for ground velocities between $60 \mathrm{~s}-50 \mathrm{~Hz}$ and OBS 04 (lost), 05 and 06 were equipped with Trillium Compact, broadband seismometers with a flat instrument characteristic between 120s $-100 \mathrm{~Hz}$. All OBSs have the same hydrophone (High-Tech-Inc HTI-04PCA/ULF, flat in the range of $100 \mathrm{~s}-8 \mathrm{kHz}$ ). All channels were recorded with a sampling rate of $50 \mathrm{~Hz}$. 
The OBSs' positions were calculated using active acoustic techniques (Shiobara et al., 1997) and the timing errors were corrected (Supplementary Material) by using the daily differences between noise cross-correlation Green's functions and a reference (Hannemann et al., 2013). The vertical component is realigned by a gimbaling system (Stähler et al., 2016) and the horizontal components of every OBS have been orientated (Supplementary Material) such as to correlate the radial and the vertical component of strong Rayleigh waves from shallow teleseismic earthquakes (Stachnik et al., 2012; Zha et al., 2013). The instrument response (Scherbaum, 2001; Haney et al., 2012) has been removed by deconvolving all of the channels to true ground velocity and the horizontal components have been rotated along the great circle arc of the seismic wave ray path, to disclose the slowness vector of the SH wave.

We have selected 17 regional $(150 \mathrm{~km}<$ distance $<500 \mathrm{~km})$ earthquakes with magnitudes in the range $2<\operatorname{mbLg}<5$, recorded during the deployment. The earthquakes selected were located (further details in Cabieces et al. (2020)) with the non-linear location algorithm NLL (Lomax et al., 2001; Lomax et al., 2009) considering a flat Earth and using the first arrivals (P-wave and S-wave) in the OBSs' array and in land stations. The Earth model used to carry out the locations is a regional 3D model (Grandin et al., 2007); composed by cubic cells of 1 x 1 x $1 \mathrm{~km}$ reaching a depth of $60 \mathrm{~km}$ in the region $\left(14^{\circ} \mathrm{W}-4^{\circ} \mathrm{W}, 34^{\circ} \mathrm{N}-38^{\circ} \mathrm{N}\right)$. The locations of the estimated epicenters have a maximum horizontal uncertainty of $13 \mathrm{~km}$ (size of the semi-major axis of the uncertainty ellipse, estimated at 90\% confidence level).

\section{Methodology}

In this section, we firstly describe the characteristics of the array and its performance and then, we outline the CWT methodology, the Amplitude methods (STA/LTA and Envelope). We briefly explain the beamforming and the parametrization in the Supplementary Material

\subsection{Array Performance}


The Array response function (ARF) which depends on the wavenumber vector $\boldsymbol{k}$ and the frequency $\mathrm{f}$, helps to evaluate the performance of the array for a range of frequencies, given a particular wavefront (Nawab et al., 1985; Ruigrok et al., 2017) and a particular array geometry configuration. A test has been carried out for different frequency bandwidths in order to analyze the performance of the array with the five remaining OBSs (e.g., Fig. 2).

The most important parameter of the array geometry is the aperture (A) of the array, in our case $\mathrm{A}=80 \mathrm{~km}$, which determines the maximum wavelength that it will be able to resolve. Notice that the width of the main lobe is responsible for resolving the slowness S-wave front unambiguously (Fig. 2a). It is also important to estimate the frequency bandwidth in which the analyzed array can attain a relatively good slowness resolution and to derive the limits of the maximum resolvable slowness range (increment distance in the ARF between two contiguous sidelobes), otherwise a wrong selection of the bandwidth may cause either an inaccurate estimation of the slowness vector or a solution trapped in a relative maximum of the slowness map (Figs. 2b and 2c).

Figs. $2 \mathrm{a}$ and $2 \mathrm{~b}$ show the ARF for the frequency bands $[0.05-0.1] \mathrm{Hz}$ and $[0.2-0.3] \mathrm{Hz}$, respectively. In Fig. 2a an unambiguous main lobe is observed in contrast to Fig. $2 \mathrm{~b}$ with the sidelobes near the inner ring $(\mathrm{S}<0.1 \mathrm{~s} / \mathrm{km}$, the limit of the slowness for teleseismic body waves). Fig. 2c shows the ARF for the frequency band $[0.4-0.5] \mathrm{Hz}$, slightly above the spatial aliasing limit $(f \approx 0.3 \mathrm{~Hz})$. Fig. $2 \mathrm{~d}$ shows the slowness map of the ARF for the frequency band [4-4.5] Hz, which is completely saturated due to spatial aliasing.

The array configuration also plays an important role as it shapes the main lobe. In our case, the main lobe is quite similar to an ellipse with a major N-S axis orientation, which means that there is higher slowness resolution for E-W azimuths. The last important factor which is also related to the array geometry is the number of sensors, because due to more sensors there is a better ability to discriminate waves with different slowness vectors. In addition, the number of sensors 
determines the theoretical SNR improvement or array gain, which is proportional to the square root of the number of sensors (Rost and Thomas, 2002). As a preliminary evaluation, the OBS array may be appropriate to measure the slowness of coherent teleseismic phases from any azimuth.

As shown in the ARF (Fig. 2d), the configuration of the OBS array sensors does not unambiguously discriminate slowness vectors for the frequency range of regional earthquake body waves. The spatial aliasing, caused by the large inter-sensor distances, can affect our slowness estimation for frequencies higher than $f \approx 0.25 \mathrm{~Hz}$ (see Figs. 2c and $\mathrm{d}$ for the frequency bands $[0.4-0.5]$ and $[4.0-4.5] \mathrm{Hz}$, respectively). On the contrary, there exists a relative narrow main lobe for low frequencies $(f<0.25 \mathrm{~Hz})$ on the ARF, and far from ambiguous secondary lobes, shown in Figs. 2A and 2B for the frequency bands $[0.05-0.1][0.2$ $-0.3] \mathrm{Hz}$, respectively.

\section{FIGURE 2}

In summary, the ARF provides us with an idealized array behavior and we find that with a minimum number of sensors $(n=5)$ the large aperture array can analyze earthquakes with lowfrequency energy content such as teleseismic phases $(f<0.3 \mathrm{~Hz})$. However, the array is useless

to detect and estimate the slowness vector from regional seismic phases because of spatial aliasing and degradation of the waveform coherency across the array, where typical dominant frequencies are in the range of 2 to $12 \mathrm{~Hz}$.

\subsection{Continuous Wavelet Transform}

The main target of the methodology presented in this paper is to find impulsive functions that represent the incoming wave onset and preserve its similarity in the frequency bandwidth in which we can apply the beamforming procedure. These Characteristic Functions (CFs) are 
simply a representation of the actual arrival times of the seismic phases that facilitate the determination of the slowness vector, especially for arrays with few sensors. Furthermore, the use of CFs can help improve the detection of the phase arrival times for events with very low SNR and/or emergent onset.

This methodology will be focused on deriving the CFs through the common characteristics and similarity of patterns in the power density time-frequency plane by a wavelet transform analysis. The complex nature of the seismic waveforms, which are transient non-stationary signals, makes it difficult to extract the true power density. Wavelet Transform is a well-proven tool to analyze the evolution of the frequency content as a function of time (Daubechies and Bates, 1992; Mallat, 2009),

In order to estimate a correct $\mathrm{CF}$, we need a wavelet transform with the ability to separate instantaneous frequencies as well as time resolution to provide a sufficient time-varying signal change. We use a quasi-analytic wavelet $\psi(t)$ (being the Fourier Transform $\hat{\psi}(f) \approx 0$ for $f<$ 0); more precisely, the normalized Morlet wavelet defined as,

$\psi(t)=\frac{1}{\left(\sigma_{t}^{2} \pi\right)^{1 / 4}} e^{-\frac{t^{2}}{2 \sigma_{t}^{2}}} e^{i 2 \pi f_{c} t}$

where

$\sigma_{t}=\frac{w}{2 \pi f_{c}}$

here $f_{c}$, is the center frequency of the Morlet wavelet, $w$ the number of cycles and $\sigma_{t}$ the scale of the Morlet wavelet. The Morlet wavelet (Eq. 7) is a complex sine wave modulated by a Gaussian function. A complex wavelet is chosen due to its ability to accurately analyze oscillatory signals, such as seismic waves, preserving the magnitude and the phase information 
(Bayram, 2013). On the other hand, the dilatation of the wavelet is managed by the number of cycles $(w)$, and it is related to the scale factor $\sigma_{t}$ (width of the Gaussian function) by Eq. 8 .

The number of cycles is set to control the trade-off between temporal and frequency resolution by defining the width of the Gaussian time window. In Fig. 3, we show the scalogram for the vertical component of an earthquake of magnitude $m_{b L g}=4.0$ and at an epicentral distance of $230 \mathrm{~km}$ recorded at OBS05. The scalogram (Rioul and Flandin, 1992) in Fig. 3 has been estimated for the frequency band $[1-25] \mathrm{Hz}$ increasing the number of cycles from 5 to 8 (further details of parameter settings in the Supplementary Material). We observe that the scalogram highlights the P-wave phase arrival as a maximum of energy between $[2-8] \mathrm{Hz}$ and the arrival of the S-wave in the frequency band [2 - 12] Hz.

\section{FIGURE 3}

Afterwards, we find the CFs by calculating the logarithmic differences between contiguous components of the scalogram along the time axis in the frequency range of interest and then stacking those differences to obtain a time-domain function, $\mathrm{A}(\mathrm{t})$. This is done following

$$
A(t)=\frac{1}{n} \sum_{f=f_{o}}^{f n}\left\{\log \left(P_{w} f(t+1, f)\right)-\log \left(P_{w} f(t, f)\right)\right\}
$$

here, $n$ is the number of samples and $f_{o}, f_{n}$ are the lower and the upper-frequency limits of interest and $\mathrm{P}_{\mathrm{w}}$ is the scalogram (i.e., $P_{w} f(t, f)<1$ after deconvolving to true ground velocity). Taking the logarithmic differences is a simple way to decrease the dynamic scale of the scalogram components. 
On the one hand the stack is needed to reduce the loss of power information for the higher frequencies due to the shape of the scalogram and on the other hand, because a nonorthogonal wavelet analysis such as is used in this study is highly redundant at large scales, it may cause imprecision in power estimations for high frequencies. Finally, we simply filter every $A(t)$ with a zero-phase low pass filter to obtain the CFs. This smoothing will let us find a function with an energy content adapted to our array and also to produce CF coherency.

An example of the smoothing effect is shown in Fig. 4. Data corresponding to the record of Earthquake T16 (Table 1) from the vertical component of the OBS02 are displayed at the top (Fig. 4A) for a 250s wide time window. The bottom of Fig. 4 displays the CFs which are derived after filtering $\mathrm{A}(\mathrm{t})$ with an order 3 zero-phase Butterworth lowpass filter for three different corner frequencies, where the red CF was low passed filtered using a corner frequency of 0.05 $\mathrm{Hz}$, the green $\mathrm{CF}$ of $0.1 \mathrm{~Hz}$, and the yellow $\mathrm{CF}$ of $0.15 \mathrm{~Hz}$, respectively.

\section{FIGURE 4}

The process to obtain the CFs removes all the phase information but allows reliable determination of the phase arrival time and derives surrogate waveforms in the frequency bandwidth in which spatial aliasing can be avoided in subsequent beamforming.

Fig. 5 summarizes the process of deriving the CFs from the CWT technique implemented for Earthquake T1 (Table1). Fig. 5 (right panels) show the scalograms computed for the bandwidth [2 - 12] Hz with a constant number of cycles set to eight. The seismograms of the OBS array is displayed together with the underlying CFs in Fig. 5 (left panels). The waveforms are incoherent from site to site in the array, however the scalograms are more uniform, which helps to build coherent CFs. The CFs display relative maximum values at the times of the phase arrivals as well as an energy content suitable to facilitate the beamforming process to estimate 
the slowness vector. All in all, the CWT methodology will permit the exploitation of the similarity of scalograms among the sensor's array to avoid relying on the underlying coherency of waveforms.

\section{FIGURE 5}

\subsection{Amplitude Method (AM)}

As we mentioned before, we are trying to detect earthquake signals and then estimate the slowness vector, transforming the original raw seismograms into CFs. Implementing the CWT method, we find relatively accurate (the peaks of CFs approximate the phase arrival time with relative low uncertainty), reliable, and well-defined CFs (Fig. 6). However, for comparison and to test a faster scheme to estimate the CFs, we follow Grigoli et al. (2013) and Dahm et al. (2013) took advantage of the classical STA/LTA method (Short Term Averaging/Long Term Averaging) to get a primary detection of the event and a very fast slowness vector estimation. The STA/LTA ratio of the signal $y$, is derived by,

$$
S T A=\frac{1}{N_{s}} \sum_{n=1}^{N s} y_{n}
$$

and

$$
L T A=\frac{1}{N_{L}} \sum_{n=-N_{L}}^{0} y_{n} .
$$


Where $N_{S}$, is the number of samples in the STA time window $\left[1 N_{S}\right]$ and $N_{L}$ is the number of samples in the LTA time window $\left[-N_{L} 0\right]$.

The process to calculate the CFs by the STA/LTA, (Figs. 6D and E), starts applying a high pass filter to the signal to clean it of low-frequency noise and to calculate the STA/LTA. The STA works by measuring the "instant" amplitude of the seismic signal (Trnkoczy, 1999) while the LTA takes care of average seismic noise. This strategy permits us to determine the precise instant of the incoming abrupt energy change from the wavefront. Finally, the temporal traces obtained from the ratio STA/LTA are filtered with a low pass filter to estimate the smooth timevarying power of the signal, $\mathrm{CF}$.

In parallel, the envelope of the seismic traces $|H(t)|$ can be calculated from the analytic signal (Oppenheim and Schafer, 2010),

$$
H(t)=y(t)+i y_{h}(t)
$$

where $y_{h}(t)$ is the Hilbert transform of the trace, $y(t)$. We compute the envelope using the Python seismology toolbox ObsPy (Beyreuther et al., 2010).

The envelope (Figs. $6 \mathrm{~b}$ and c) slowly follows the signal energy changes and is stable enough to build CFs. In this sense, the analytic signal behaves like the CWT with a complex wavelet (Bruns, 2004). Both slowly follow the energy signal content and preserve the phase information (Bear and Pavlis, 1997). Finally, the envelope is also filtered with a low pass filter in order to obtain CFs. An example of this technique is shown in Fig. 6, which summarizes all the stages of the technique. Firstly, we have filtered the vertical component of Earthquake T4 (Table 1) recorded at OBS01 (Fig. 6a and 6c) by applying a high pass filter ( $\mathrm{fc}=0.5 \mathrm{~Hz}$ ) to remove lowfrequency noise and to take into account the previous estimated power spectrum of the signal. The envelope of the seismic trace (red line) is derived from the analytic signal and is shown in 
Fig. $6 \mathrm{c}$ together with the seismic signal (blue line). Then, the envelope is filtered (low pass $\mathrm{f}_{\mathrm{c}}=$ $0.15 \mathrm{~Hz}$ ) in Fig. 6d to obtain the CFs. On the other hand, the STA/LTA time function is displayed in Fig 6a (red line). The STA/LTA time function is filtered using a low pass filter at $0.15 \mathrm{~Hz}$ (Fig. 6b) to obtain the matching CF. Both of the CFs, the envelope (Fig. 6d), and the STA/LTA (Fig. 6b) are similar and they softly represent the P- and S-wave onsets. In this example, the S-wave onset is represented by the CF which has a larger amplitude than the Pwave onset in the $\mathrm{CF}$, as the signal-to-noise ratio of the $\mathrm{S}$-wave is higher than that of the $\mathrm{P}$ wave (typical feature in the oceanic waves $\mathrm{Po} / \mathrm{So}$ ).

\section{FIGURE 6}

\subsection{Epicenter determination from CFs}

The epicenter determinations by the OBS array are obtained using the back-azimuth (BAZ) that corresponds to the maximum power of the optimal slowness vector and the distance between the array reference point and the estimated epicenter. The distance is calculated by,

$$
D=\frac{\Delta t_{s-p} V_{s} V_{p}}{V_{p}-V_{s}}
$$

where $\Delta t_{s-p}$ is the difference of the arrival times for the P- and S-waves retrieved from the beam of the $\mathrm{CFs}$ for the optimal $\mathrm{P} / \mathrm{S}$ slowness vector, and $V_{p}, V_{s}$ are the mean velocity values of the P-and S-waves in the oceanic crust and upper mantle (up to $50 \mathrm{~km} \mathrm{depth}$ ). In this paper, we have estimated $V_{s} \sim 4.087 \mathrm{~km} / \mathrm{s}$ and $V p \sim 7.078 \mathrm{~km} / \mathrm{s}$ according to a 3D model (Grandin et al., 2007), averaging the velocity of the 3D-model grid cells in layers of $1 \mathrm{~km}$ depth in the region $14^{\circ} \mathrm{W}$ to $5^{\circ} \mathrm{W}$ and $34^{\circ} \mathrm{N}$ to $38^{\circ} \mathrm{N}$, and then calculating the mean of the velocity layers.

\section{Results}

The methodology has been tested by comparing epicenters derived from the CWT methodology with a set of regional earthquakes that took place during the array survey and were located 
(Cabieces et al., 2020) with the non-linear location method NLL (Lomax et al., 2009) and using the 3D model of Grandin et al. (2007). Table 1 shows the numerical results of locations (E1, Array method and E2, non-linear method) along with the back azimuth and slowness with their uncertainties calculated from the tangents to the main lobe of the slowness map at $5 \%$ below the maximum power.

The set of epicenters located with NLL is the reference to evaluate the accuracy and possible deviations of the BAZ and slowness determined by the CWT array methodology. These earthquakes were selected to cover many different azimuths, magnitudes [2.0 to 5.0] $m_{b L g}$ and epicenter distances. The epicenter distances ranged from 150 to $500 \mathrm{~km}$ from the array center, keeping in mind that because of the plane wavefront assumption, we can only estimate the slowness vectors of epicenter distances from more than two times the array aperture (Almendros et al., 1999). In Fig. 7 the epicenters determined by the OBS array (red circles) are shown together with the set of selected epicenters (grey circles) and its uncertainty horizontal ellipses (grey ellipses). The minimum distance between E1 and E2 is $1 \mathrm{~km}$, the maximum is $21 \mathrm{~km}$ and the mean is $12 \mathrm{~km}$ (excluding the anomalous results of Earthquakes T7 and T12).

\section{FIGURE 7}

\section{TABLE1}

Fig. 8 is a polar representation centered on the array, intended to better visualize the BAZ difference between the back azimuth of solution E1 and E2 (Table 1, BAZ Difference). The BAZ Difference is highlighted in a color scale showing the range of values for the P-wave on the left and S-wave on the right side. The symbol size is proportional to the apparent slowness, with values from $0.11 \mathrm{~s} / \mathrm{km}$ to $0.13 \mathrm{~s} / \mathrm{km}$ for P-waves and $0.18 \mathrm{~s} / \mathrm{km}$ to $0.22 \mathrm{~s} / \mathrm{km}$ for S-waves. 


\section{FIGURE 8}

BAZ difference values for the P-wave tend to be slightly lower than those for the S-wave with a maximum for the $\mathrm{P}$-wave of $7^{\circ}$ and a maximum for the S-wave of $10^{\circ}$. Both of them have the same tendency toward positive differences and even sharpen for the S-wave in the angular sector $\left[60^{\circ}-120^{\circ}\right]$. The other angular sector with high azimuth deviation is the sector between $\left[270^{\circ}-330^{\circ}\right] \mathrm{deg}$. The overall results in the BAZ difference are a mean value of a $\left(1.5^{\circ}\right)$ for the P-wave with a standard deviation of $3.0^{\circ}$ and for the S-wave of $3.0^{\circ}$ with a standard deviation of $5.0^{\circ}$, respectively.

\section{Discussion}

The CWT application herein shows that it is possible to detect the seismic signal and determine with good precision the slowness vector from regional earthquakes as seen in the results section (Table 1). First, we discuss the efficiency of the CWT methodology over the conventional BBFK array technique outlining the most important features and then we compare the CWT method with the AM.

In Figs. $9 \mathrm{~b}$ and $9 \mathrm{c}$ we show the semblance coefficient for a sliding time window (24 s) using the unfiltered seismic signal beam of Earthquake T9 (Table 1). A stable solution is not found for the slowness or back azimuth in the typical frequency seismic bandwidth $[5.5-6.5] \mathrm{Hz}$ using BB-FK. Figure 9 summarizes both difficulties, the spatial aliasing problem and the impossibility of finding a reliable beam power from incoherent traces. Next, we compute the BB-FK for the same earthquake but using sliding windows $(24 \mathrm{~s}$, bandwidth $[0.05-0.1] \mathrm{Hz})$ from the CFs obtained with the CWT method (Fig. 9d) to derive a stable and reliable solution 
for the slowness and back azimuth (Figs. 9e and 9f). Figure 9d displays how the Po and So onset is detected in the CFs' beam (red line) along with the beam of the raw signals.

\section{FIGURE 9}

In Figure 10 and 11, we focus on the differences and limitations between the AMs and the CWT with the help of the T2 earthquake example. Previous to the computation of the AMs and CFs, we applied a zero-phase high pass filter $(\mathrm{fc}=0.5 \mathrm{~Hz}$ ) to the raw seismic signals intended to remove the oceanic seismic noise. Moreover, the CWT is applied in the bandwidth [0.5 - 25] $\mathrm{Hz}$ to be able to compare both methodologies and to take into account the power spectrum of the T2 earthquake. The parameters of the CWT and AM method are not optimized for this test, we simply use the common parameters (see parameter settings section) $\omega_{0}=8$ in the CWT and the ratio of the STA/LTA window length to $1 / 40$.

As mentioned in the methodology section, the AM was designed to very quickly detect the seismic signal and to retrieve a primary estimation of the slowness vector. But occasionally, some earthquake first arrivals cannot be detected by the STA/LTA algorithm or by the envelope with low SNR conditions (Fig. 10). Nevertheless, thanks to the convolution narrow filter effect, the CWT can very accurately extract the CFs from the seismic energy with low SNR and it also allows the detection of transients in signals with diffuse energy over a wide frequency band. Fig 10 shows the detection comparison between the CWT and the AM methods, where it is remarkable that while the maxims displayed (red picks) by the CWT CFs are in agreement with the manual picks (black pick), the AM methods (green line STA/LTA and blue line) are not able to detect the emergent arrival of the Po.

FIGURE 10 


\section{FIGURE 11}

In terms of computation time cost CWT has a slight disadvantage compared to the AM, although that disadvantage can be alleviated by pre-calculating a bank of atoms (in our case banks of Morlet wavelet atoms) before the implementation of CWT for the frequency band of interest. For example, the computation time ratios between the CWT and the AM methods for a $24 \mathrm{~h}$ seismogram (sampling rate 50 samples/s) using a pre-calculated bank of atoms are

$$
\begin{aligned}
& \frac{V_{c w t}}{V_{\text {sta_lta }}} \approx 18 \\
& \frac{V_{c w t}}{V_{\text {envelope }}} \approx 1.4
\end{aligned}
$$

where $V_{c w t}, V_{\text {sta_lta }}, V_{\text {envelope }}$ are the processing speeds of $24 \mathrm{~h}$ data for the CWT, STA/LTA, and envelope methods. Nevertheless, $V_{c w t}$ for this example is approximately $1.6 \mathrm{~s}$, which shows that the CWT methodology is also feasible for the analysis of large amounts of datasets.

It is also remarkable in the example we are analyzing that the S-wave detection is delayed in the AM (Figs. 11b and 11c). This delay is likely caused by the contamination of the S-wave by the late P-wave coda, mostly as a consequence of multiple scattering in the oceanic lithosphere. In this sense, if we want to avoid problems in the application of the AM implementation and boost its performance, we likely need to apply time correction terms to the estimated travel times.

A test has been carried out to analyze the possibilities of the CWT methodology as a detector for low SNR signals. We select the OBS06 vertical record of Earthquake T1 to compute the CWT (Fig. 12a) with a number of cycles varying in the range [5 - 10] for the frequency band [2 - 8] Hz. The seismogram has a relative emergent Po phase onset with a smaller amplitude than the So phase and it also has a significant long Po coda that partially masks the So onset. 
The test starts with a gradual contamination of the signal adding white gaussian noise from -85 up to $-5 \mathrm{~dB}$ of the maximum power of the signal in steps of $5 \mathrm{~dB}$ (Fig. 12b). In parallel, the CFs are estimated through the CWT methodology in each iteration. Fig. 12d displays all CFs derived for each iteration highlighting the $\mathrm{CF}$ (red line) retrieved with the maximum noise level (-5 $\mathrm{dB}$ of the maximum power of the signal). After the full contamination, the most obscured phase is the Po wave which is almost completely masked in the noise and the So onset is not distinguishable. In terms of the CFs' shape, the peak of CFs that corresponds to the So wave still preserves its shape but the maxima that corresponds to the Po onset is delayed with respect to the original Po CF maxima. The energy of the full signal is still detected in the scalogram after the noise addition, however some oscillations in the higher frequencies are partially hidden.

\section{FIGURE 12}

To sum up, the test gives an overview of the limit where the CFs lose their shapes and thus their time resolution, showing that the CWT methodology is robust enough to detect seismic signals in highly contaminated ambient noise.

Hereafter, we compare the epicenter locations obtained by the CWT method (E1) with the reference E2. In the first step, the epicentral distance between E1 and E2 is analyzed and in a second step, the BAZ and slowness deviations between those locations.

Characteristically, earthquakes between Cape Saint Vincent and the array (T3, T5, T9, and T16) are well constrained being a good reference for the comparison with array locations. However, the locations around the Gorringe Bank and those off of the west coast of Morocco are more susceptible to large location errors. From the epicenter comparison (Fig. 7), we found small location differences for all of the epicenters except for Events T7 and T12 (Table 1, Dist 14.5 
and $28.0 \mathrm{~km}$, respectively). Both epicenter determinations (E1 and E2) are consistent, with a mean inter-epicenter distance of $12 \mathrm{~km}$ and a standard deviation of $6 \mathrm{~km}$. Those results are reinforced by the overlap between the uncertainty ellipse associated with the location of the non-linear method (Table 1, L1 and L2) and the uncertainty of the array beam (beam from the center of the array toward the calculated BAZ and the width of the beam obtained through $\pm \triangle B A Z$, Table1), with the exception of Earthquake T12 (high location errors).

The anomalous BAZ differences (P-wave maximum of $7^{\circ}$ and S-wave maximum of $10^{\circ}$, Fig 8 ) in the angular sector $\left[60^{\circ}-120^{\circ}\right]$, may be explained by the poor quality of the earthquake locations in that area. Even though a 3D model was implemented to calculate the hypocenters, the lack of azimuth coverage with stations in the south yields a high latitude location error. In the other angular sector with high BAZ differences $\left[270^{\circ}-330^{\circ}\right]$, the seismic waves come from the Gorringe Bank, which is a high-velocity crust-upper mantle region both for P-and S-waves (González-Fernández et al., 2001). Moreover, the OBS array is placed in the HAP, which is characterized as a diffuse plate boundary (Jiménez-Munt et al., 2001; Palano et al., 2015) where sharp seismic wave velocity gradients may cause deviations in the wave path; however such an analysis is beyond the scope of this paper.

Figure 13 displays arrows pointing from E2 to E1 locations and the head arrow colors highlight the slowness difference, $S_{p}$ (difference between empirical slowness and estimated slowness from the CWT methodology of the P-wave). Here, we assess a remarkable odd symmetry, with slowness deviations that might be caused by the heterogeneous structure below the array (with high sediment thickness) and/or because of the complexity of the Eurasian-Nubian plate boundary, which in this region shows sharp structural changes in the elastic properties of the lithosphere (Zitellini et al., 2009; Torne et al., 2015).

FIGURE 13 
In summary, the results obtained from the epicenter locations show that the slowness vector can be calculated reliably with the new methodology. Considering the poor array performance of a large aperture array with a minimum number of sensors, the test estimations have reasonable errors.

\section{Conclusions}

The new methodology based on the Continuous Wavelet Transform confirms that the slowness vector can be estimated in an array (land or ocean bottom stations array) with a small number of stations and waveforms with a low degree of similarity. Even though, in the highest ambient noise conditions such as marine ambient noise, the CWT can detect signals and extract the wave energy content to form the CFs. A faster alternative based on the STA/LTA and the envelope has also been explored for comparison (Amplitude Method). Both methods have specific advantages regarding the estimation of the slowness vector, i.e., the multiresolution timefrequency analysis flexibility and robustness of the CWT method and the speed and simplicity of the AM.

The applicability of the methodology has been tested with an OBS large-aperture sparse array in the Horseshoe Abyssal Plain, a region with complex heterogeneities underneath the array. Despite the difficulties from pre-processing OBS data (clock synchronization and horizontal components orientation) and the poor array performance, it has been possible to estimate the slowness vector from regional phases and to derive epicentral locations with reasonable errors. From the BAZ differences, we underline the high values in a specific angular sector $\left[60^{\circ}-\right.$ $120^{\circ}$. More data analysis will be required from extended periods to better understand the azimuth anisotropy of P- and S-waves in the Gulf of Cadiz. 


\section{Acknowledgments}

With thanks to the Spanish Ministerio de Economía, Industria y Competitividad projects CGL2013-45724-C3-3-R and CGL2017-86097-R. We also thank the Royal Spanish Navy Observatory (ROA), the Instituto Geográfico Nacional (IGN) and the Instituto Português do Mar e da Atmosfera for sharing the necessary data to develop this work. We used Python 3, ObsPy (Beyreuther et al., 2010) to create the code behind the new methodology of this paper. Figures 1,9 and 14 were generated with the open-source mapping toolbox GMT (Wessel et al., 2013). MATLAB and Wavelet Analyzer Toolbox Release 2018b was also used to test the methodology and to create the rest of the figures. Computer programs that implement the array techniques are freely available and may be obtained by contacting the Spanish Navy Observatory authors. 


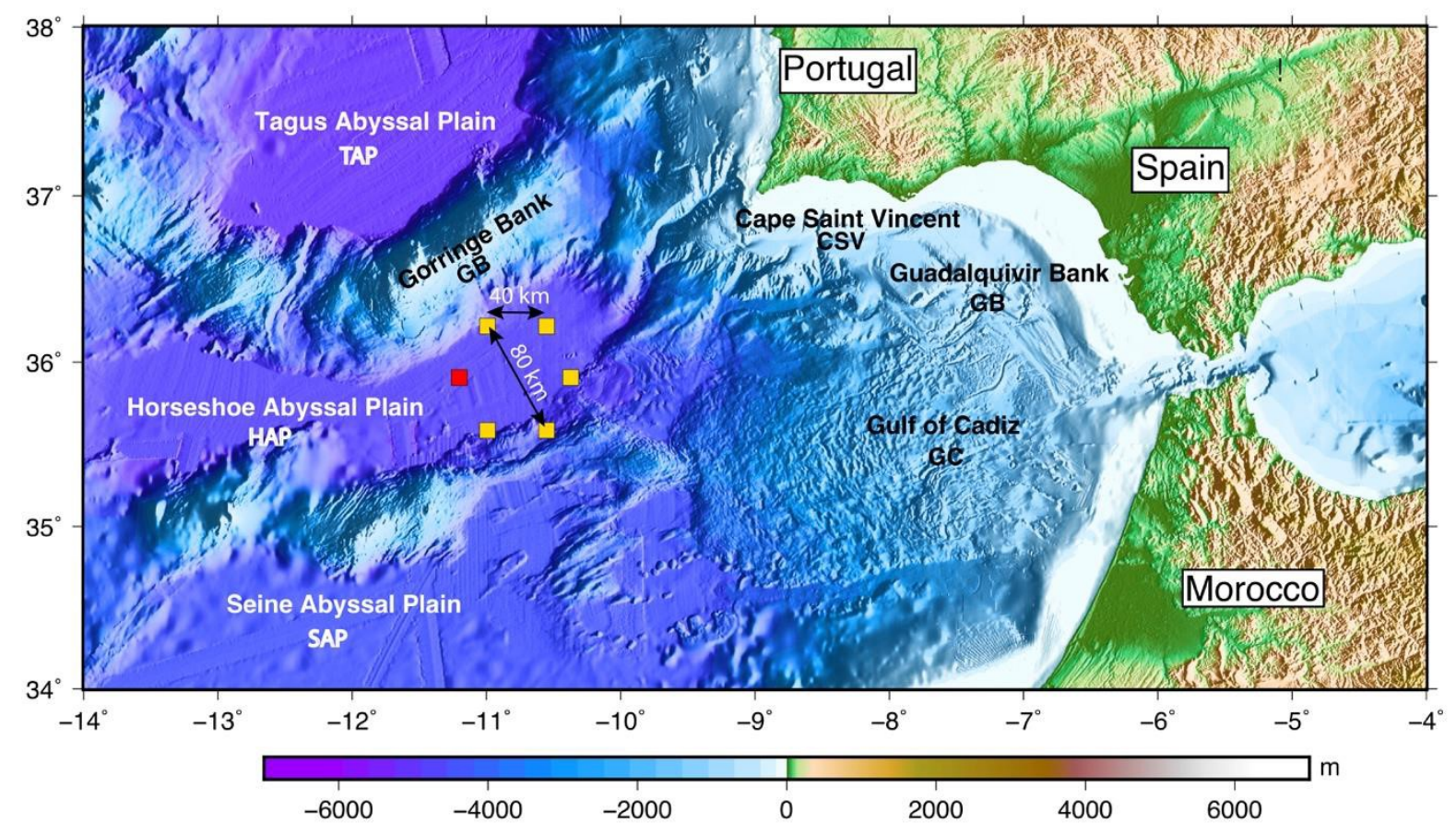

Figure 1. A, Geometry of the OBS array (orange squares, OBS04 red square) with a $40 \mathrm{~km}$ interstation-distance and $80 \mathrm{~km}$ aperture. The array reference point is placed $200 \mathrm{~km}$ from Cape Saint Vincent. The bathymetry is from the General Bathymetric Chart of the Oceans (GEBCO) digital atlas (http://www.gebco.net/). 


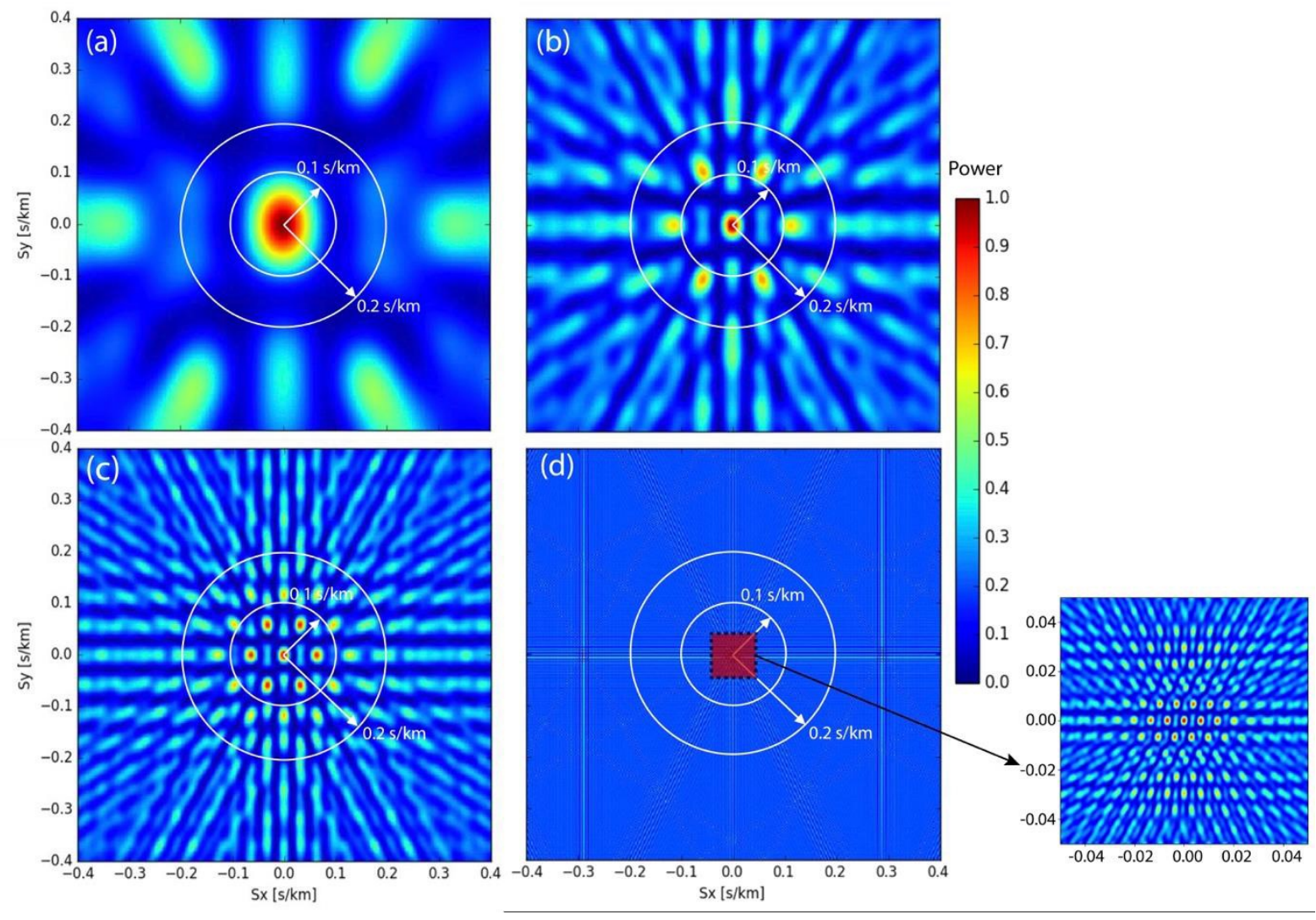

Figure 2. ARF for several frequency bandwidths. (a) ARF [0.05-0.1] Hz. (b) ARF [0.2 - 0.3]

Hz. (c) ARF [0.4 - 0.5] Hz. (d) ARF [4.0 - 4.5] Hz. The circles show the slowness limits for teleseismic body waves (inner circle $\mathrm{S}<0.1 \mathrm{~s} / \mathrm{km}$ ), $\mathrm{P}$-waves and $\mathrm{S}$-waves at regional distances $(0.1<\mathrm{S}<0.2 \mathrm{~s} / \mathrm{km})$ and $\mathrm{S}>0.2 \mathrm{~s} / \mathrm{km}$. 


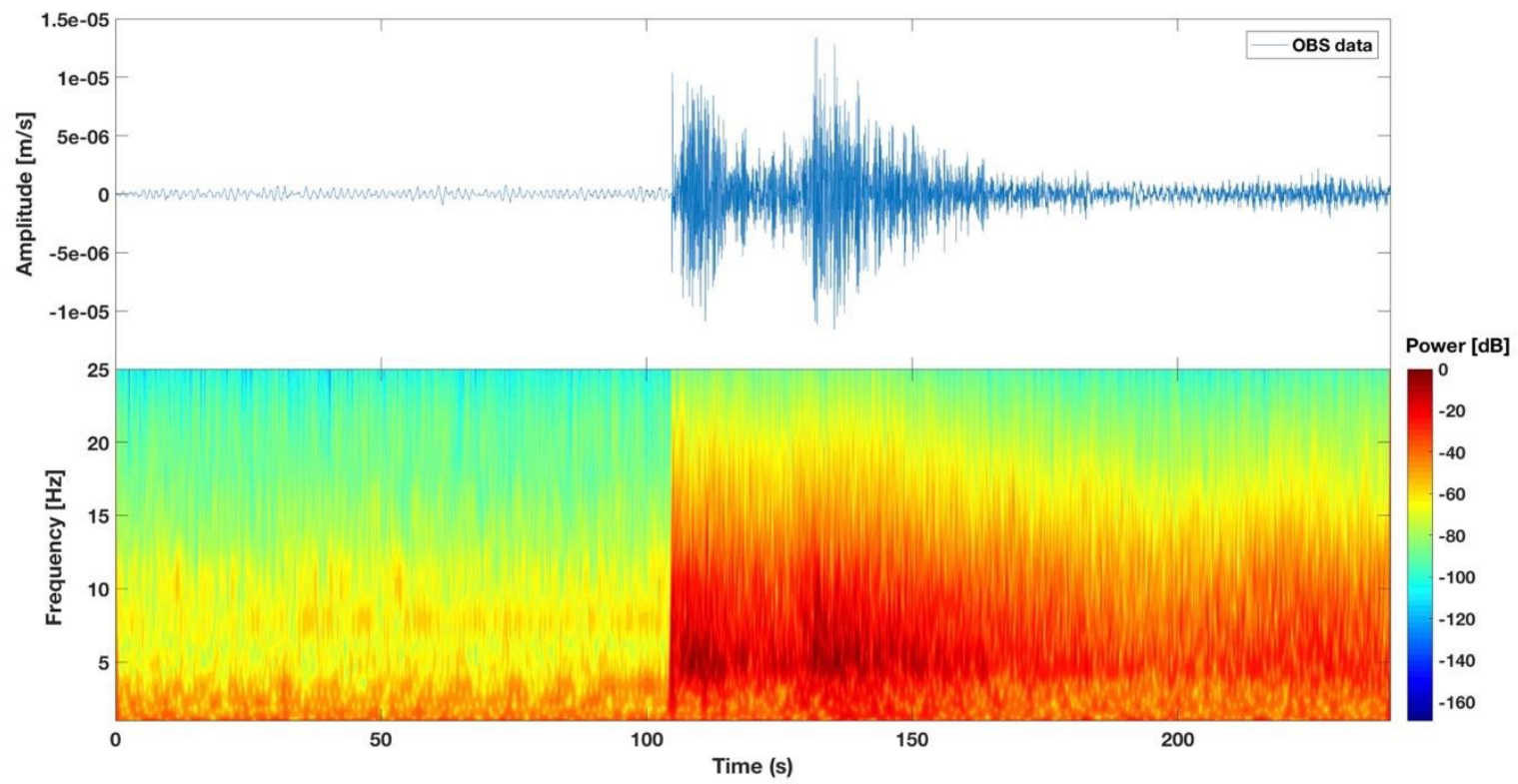

Figure 3. Scalogram ( $w=5-8$ cycles), estimated from the vertical component recorded at OBS05 station for a regional earthquake (T16, Table 1) 


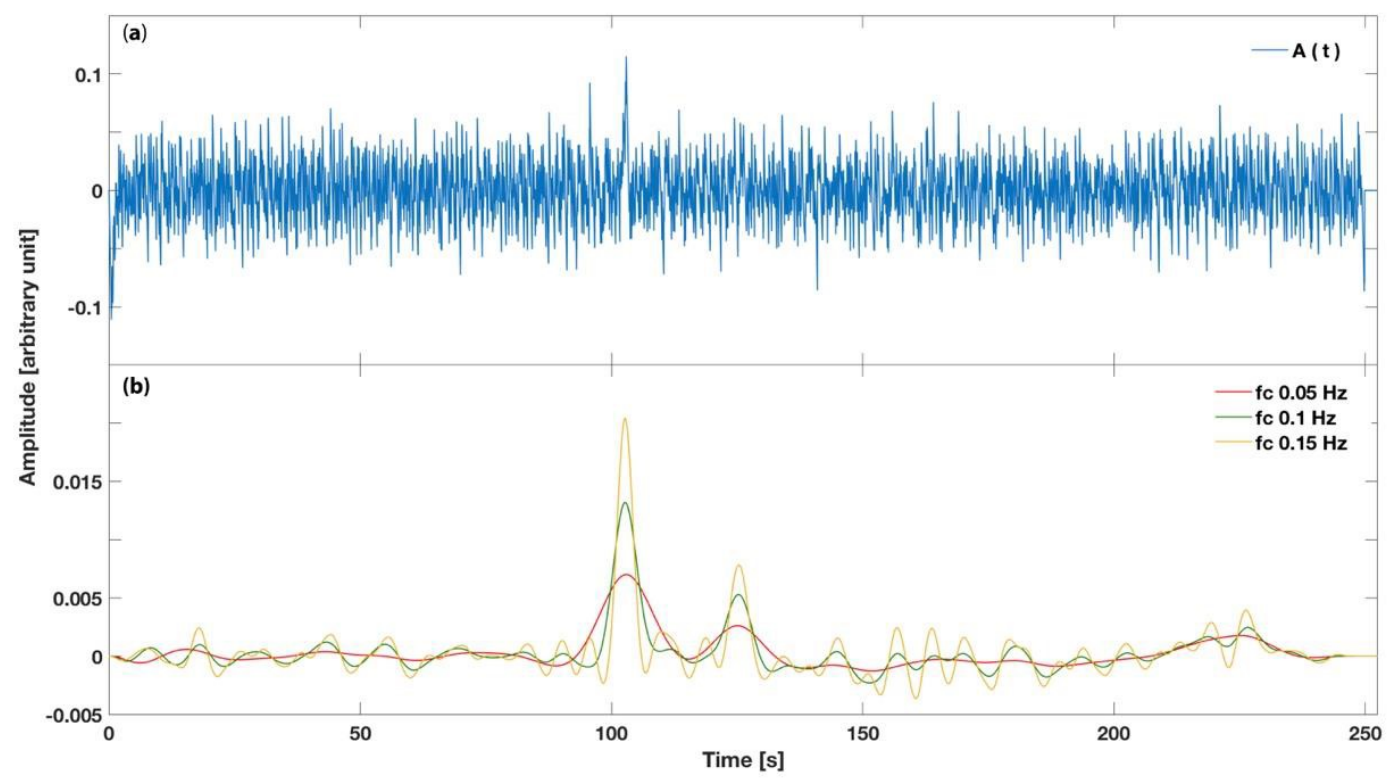

Figure 4. Example of CWT method application to the vertical component of station OBS02, for Event T16 (see Table 1). a) Raw A(t) function. b) The corresponding CF, after application of different low pass filters with corner frequencies of $0.05,0.1,0.15 \mathrm{~Hz}$. 

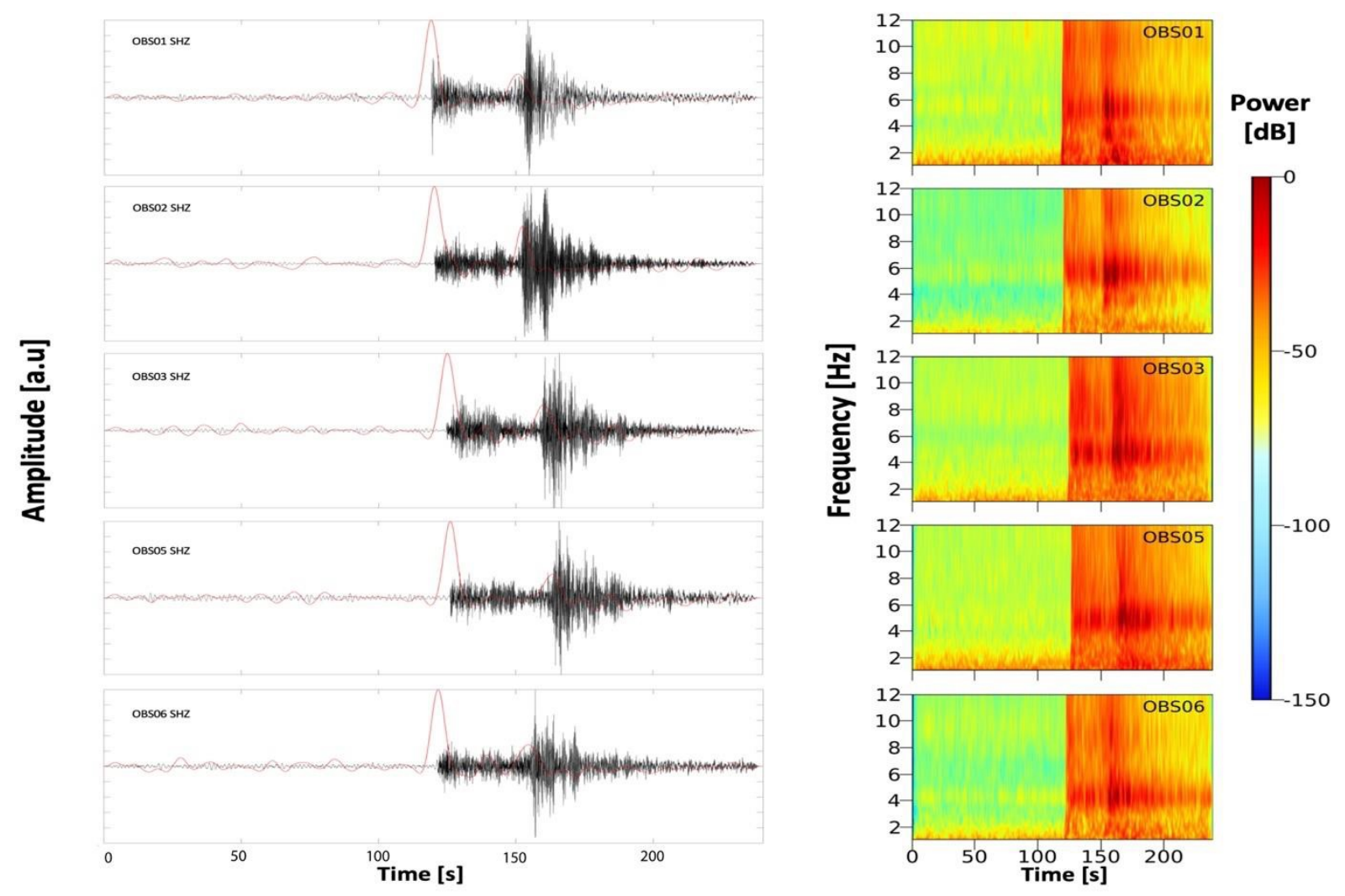

Figure 5. The left panels correspond to the seismograms (black line, normalized amplitude, and high pass filtered $\mathrm{f}_{\mathrm{c}}=0.5 \mathrm{~Hz}$ ) for every OBS (vertical component) in the array and the CFs (red line, normalized amplitude, and low pass filtered functions $A(t)$ with $\left.f_{c}=0.15 \mathrm{~Hz}\right)$. The right panels correspond to the scalograms computed from the seismograms $(\mathrm{w}=8)$ of the Earthquake T1 (see Table 1). 

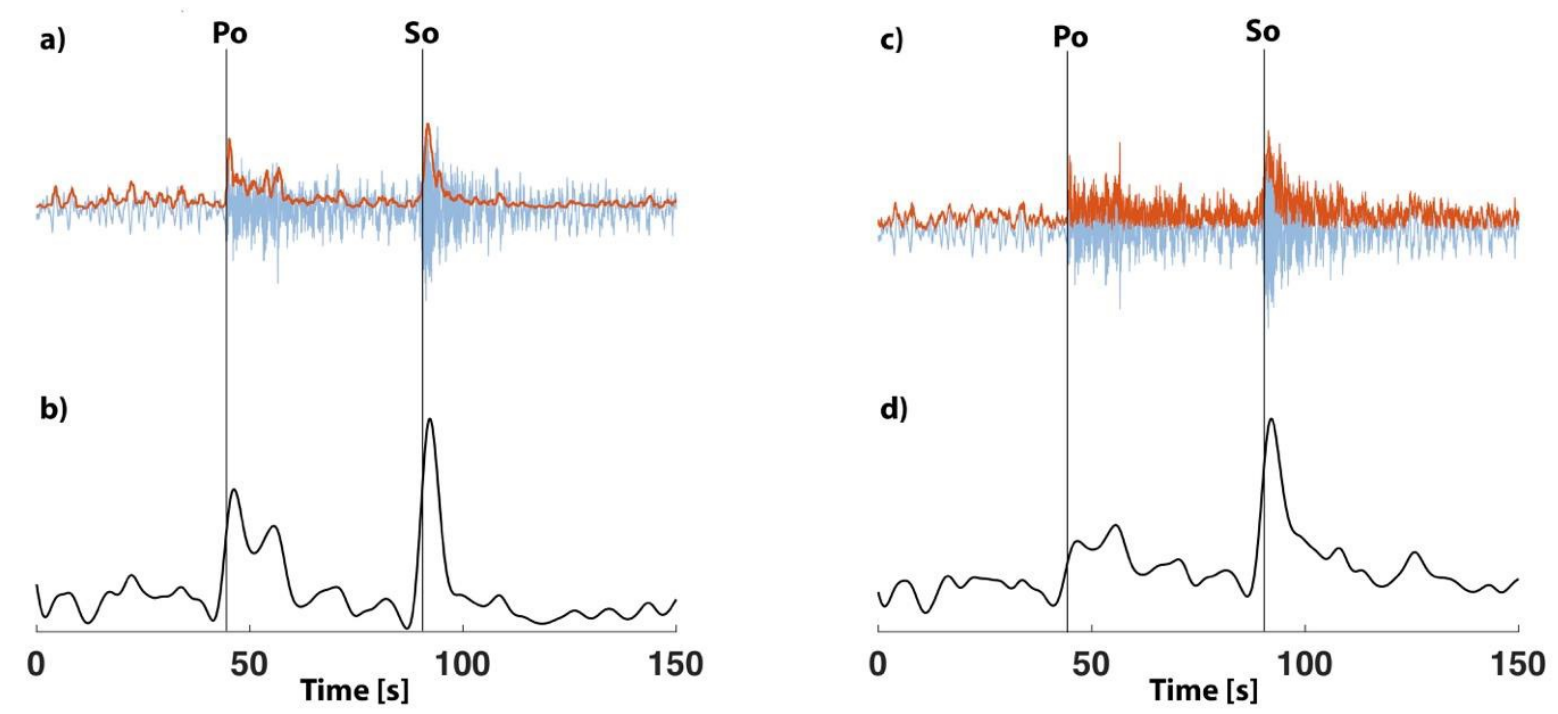

Figure 6. AM application, vertical component of station OBS01 and Event T4 (see Table 1). a) Seismic trace (blue color) and STA/LTA time function (red color). b) CF, Filtered STA/LTA time function (low pass filtered $f_{c}=0.15 \mathrm{~Hz}$ ). c) Seismic trace (blue color) and Envelope of the seismic trace (red color). d) CF, Filtered Envelope (low pass filtered $f_{c}=0.15 \mathrm{~Hz}$ ). The seismic trace has been prefiltered with a zero-phase high pass filter (fc $0.5 \mathrm{~Hz}$ ) of order 3 . 


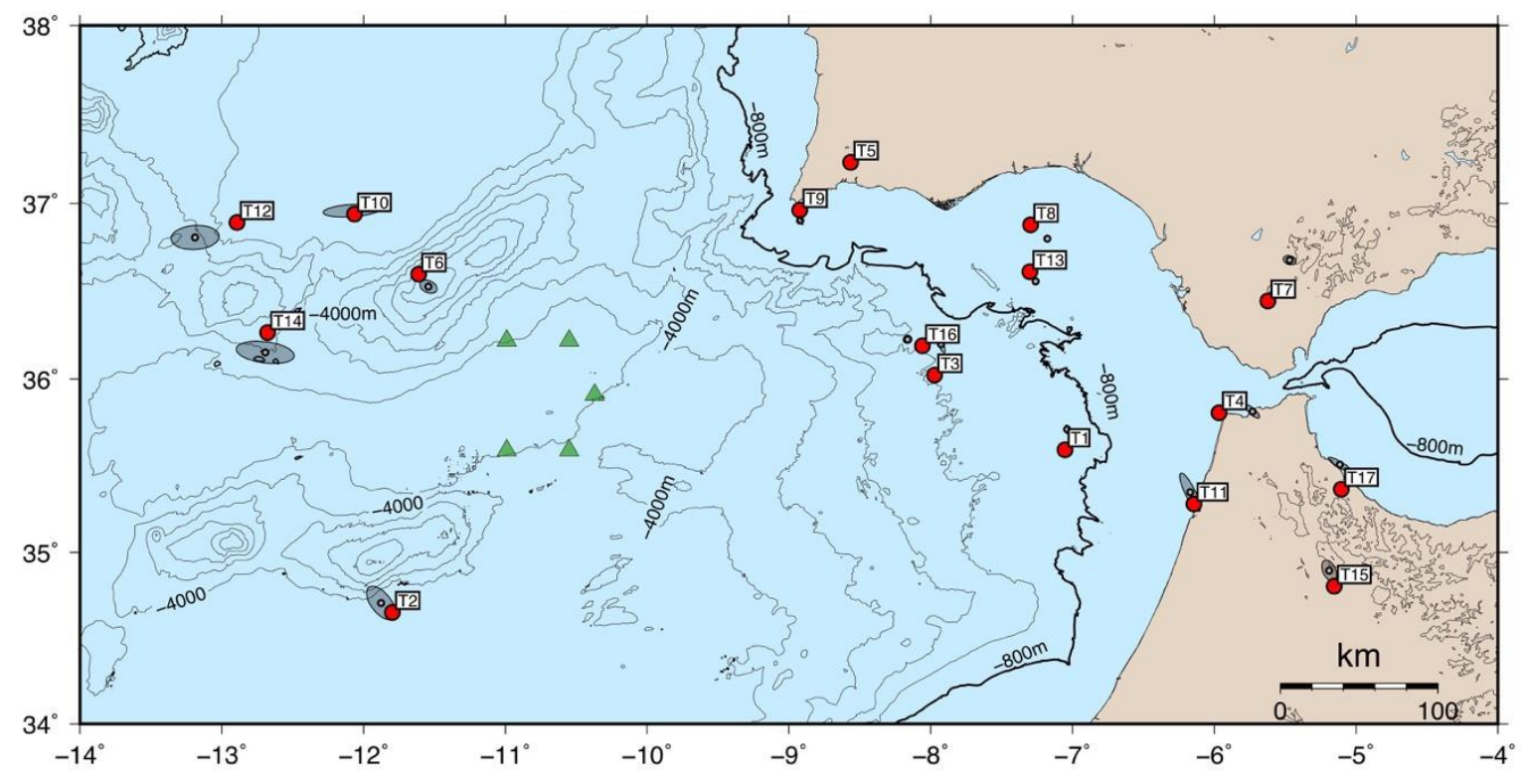

Figure 7. Distribution of epicenters located using the CWT methodology (red circles). Epicenter locations derived from the seismic network using the non-linear location method (black circles) and horizontal uncertainty ellipses (grey ellipses - length of the ellipse axes is multiplied by a factor of 2). OBS Array (green triangles). 


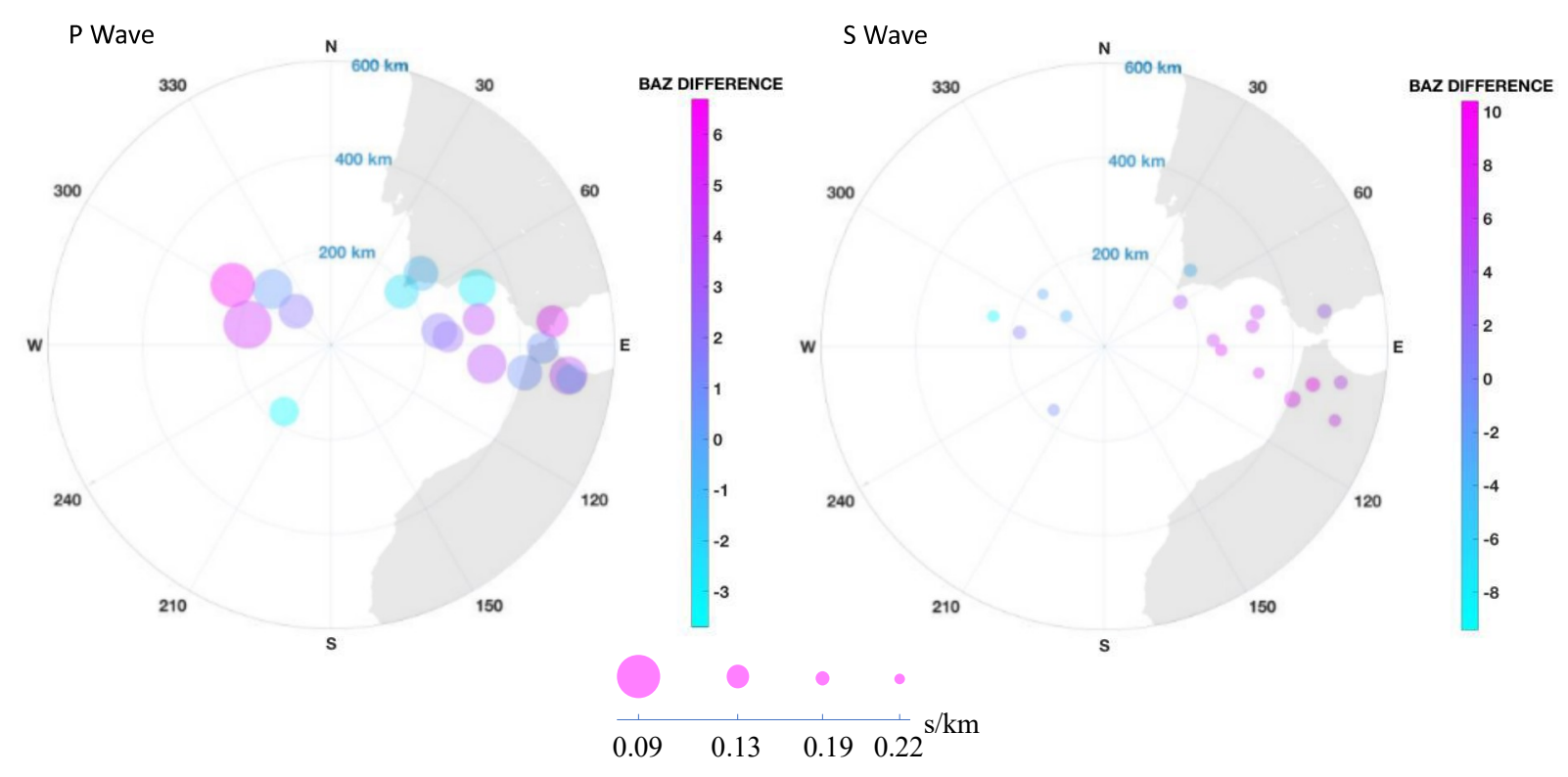

Figure 8. Left, P-wave; right, S-wave polar bubble plot. The radius is the distance from the array center. The color gradient compares the back azimuth derived from the array and the back azimuth toward the event (great circle arc) for each earthquake's epicenter. The circle size is proportional to the apparent velocity of the phase $[0.09-0.22] \mathrm{s} / \mathrm{km}$. 


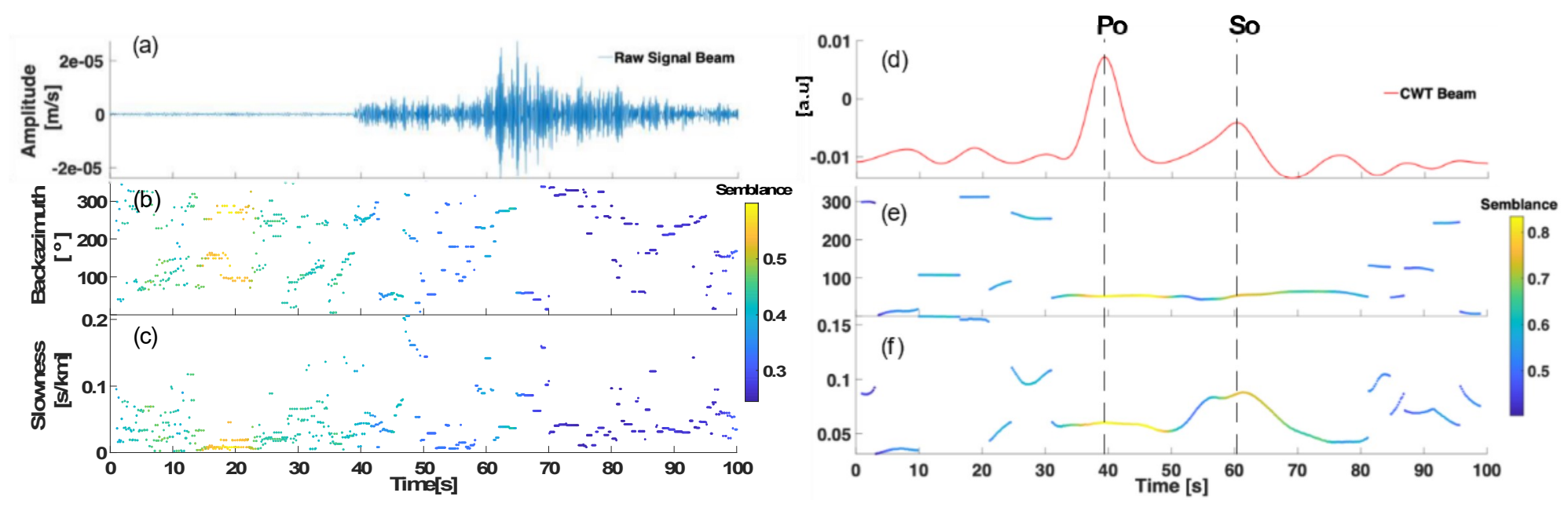

Figure 9. BB-FK analysis of Earthquake T9, vertical component. a) Beamforming of the 5 OBS raw traces. b) Back azimuth according to the maximum semblance inside a sliding time window (22 s) for the entire analysis period (100 s). c) Like b) but for slowness. d), e), and f) show the BB-FK using the CFs derived from the CWT methodology. 


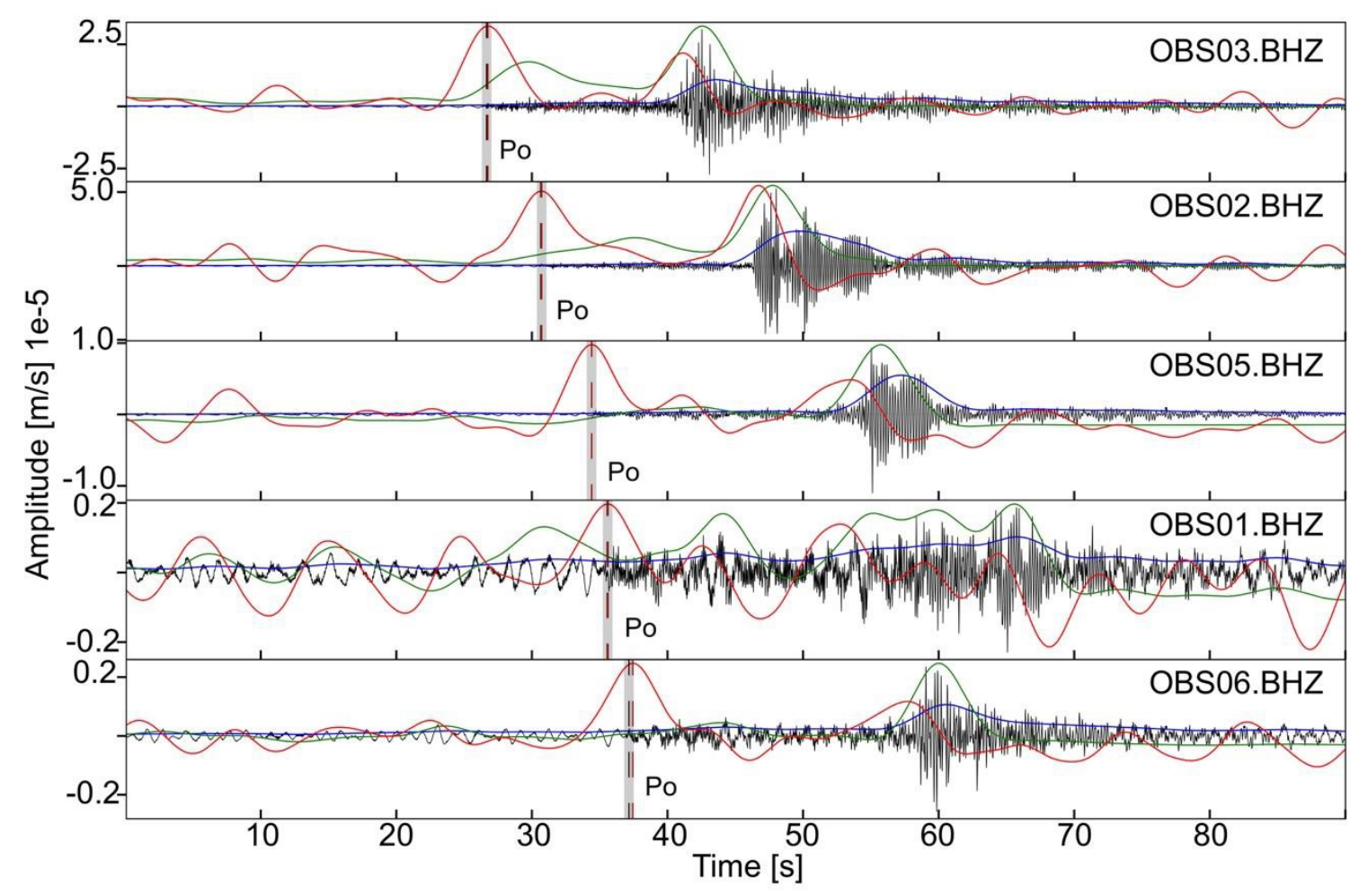

Figure 10 .Detection of the Po in the OBSs array vertical component. Red line is the CFs built from the CW, green line CFs built from the STA/LTA and blue line CFs built from the envelope. The seismograms has been filtered with a high pass filter $(\mathrm{fc}=0.5)$. Shadow areas are the errors bar associated with the manual picked Po. 


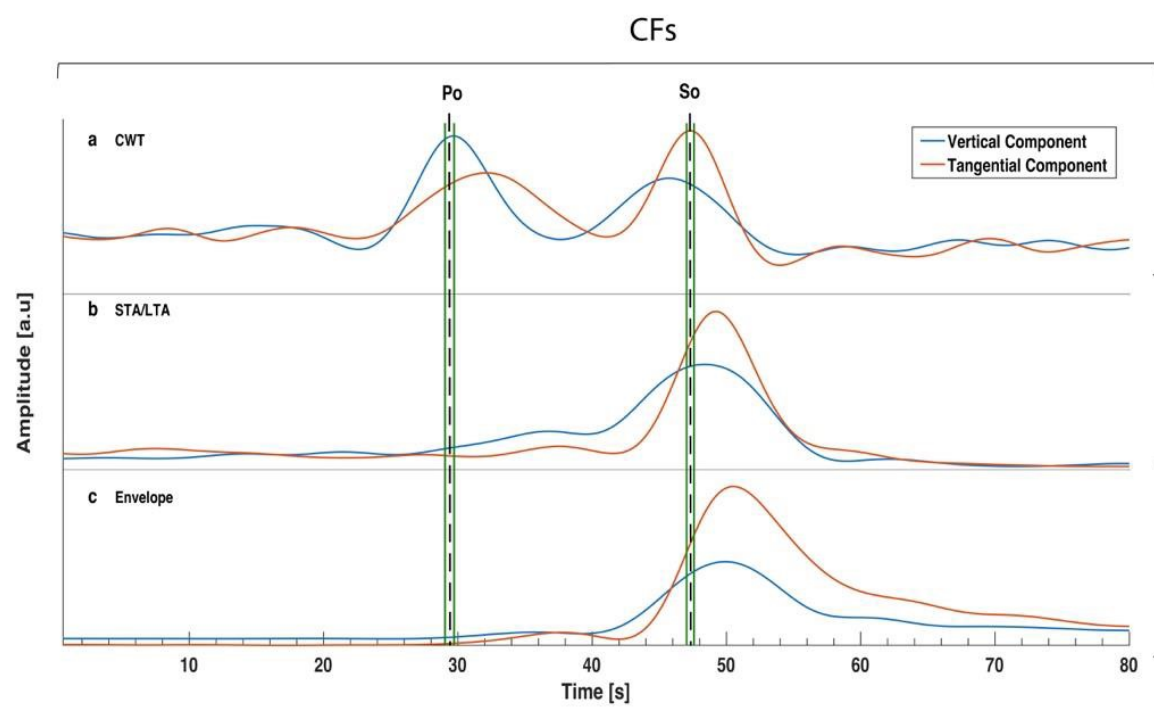

Semblance Slowness Map (s/km)

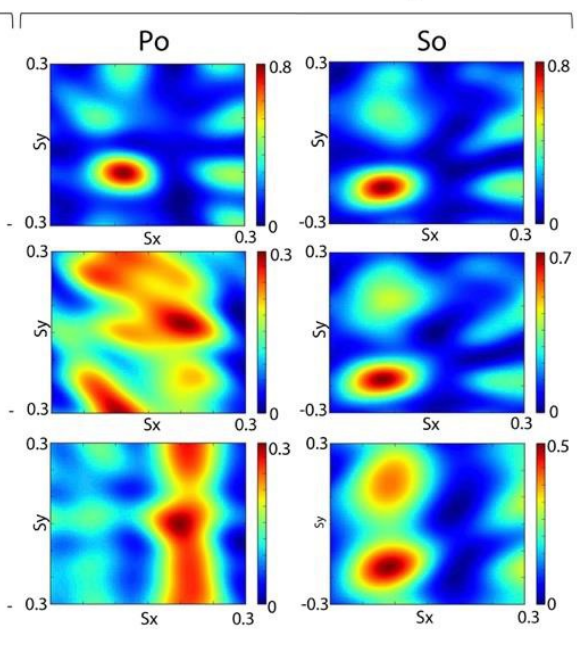

Figure 11. Earthquake T2 analysis with the new methodologies. (a) CWT-CFs beam for the vertical (blue line) and tangential (red line) component and the corresponding slowness map for the Po and So wave $\left(\omega_{0}=8\right.$, frequency band $\left.0.5-25 \mathrm{~Hz}\right)$. Po and So indicates the phase arrival times of the beamforming retrieved from the manual picks in the OBSs of the array. Green lines are the error bars $( \pm 0.3 \mathrm{~s})$ associated with the manual picked Po and So beams. (b) The same as the first row for STA/LTA-CFs beam. c) The same as a) and b) but for Envelope-CFs beam. In the amplitude method, a) and b), a high pass pre-filter was applied to the raw seismograms with a corner frequency, $\mathrm{f}_{\mathrm{c}}=0.5 \mathrm{~Hz}$. 


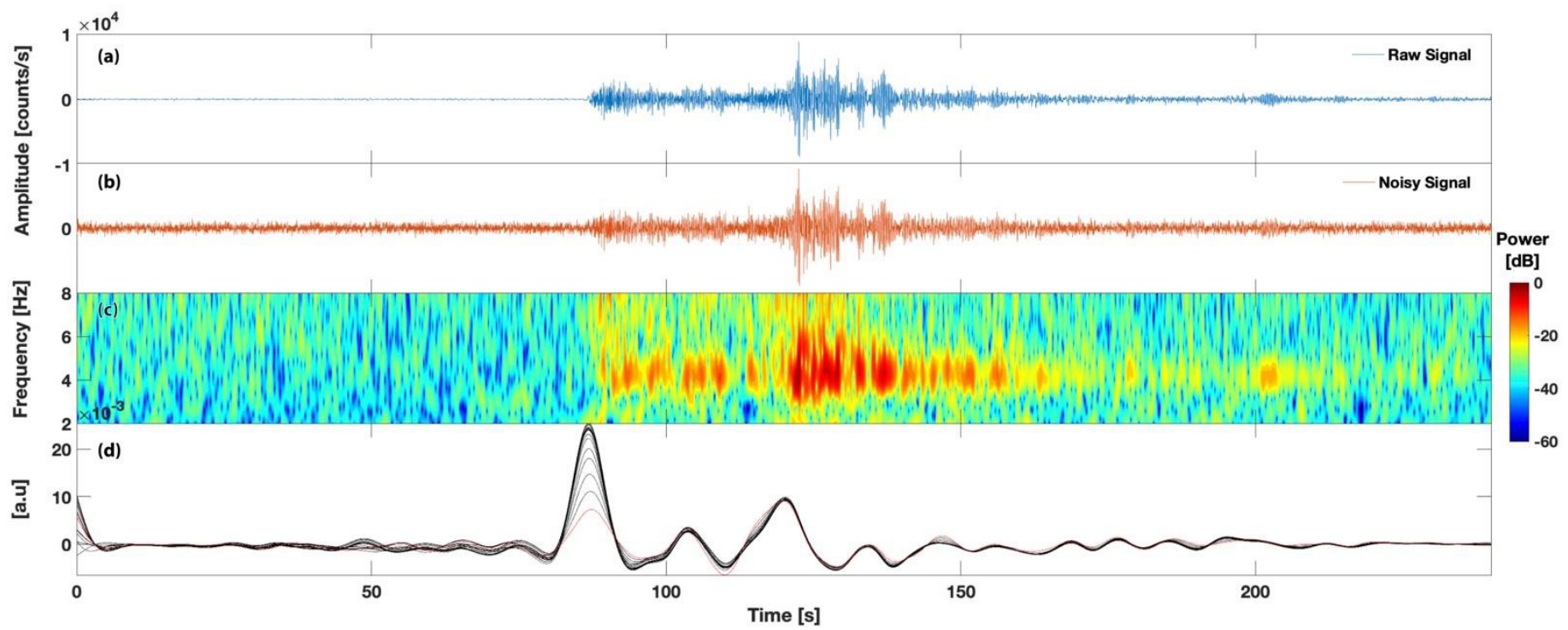

Figure 12. a) Raw signal of the regional Earthquake T1 (Table 1). b) Raw seismogram with additional white gaussian noise (-5dB of the maximum power of the signal). c) Scalogram of the contaminated seismogram. d) CFs calculated with the CWT methodology for white noise varying in amplitude from $-85 \mathrm{~dB}$ up to $-5 \mathrm{~dB}$ of the maximum power of the signal in steps of $0.5 \mathrm{~dB}$. 


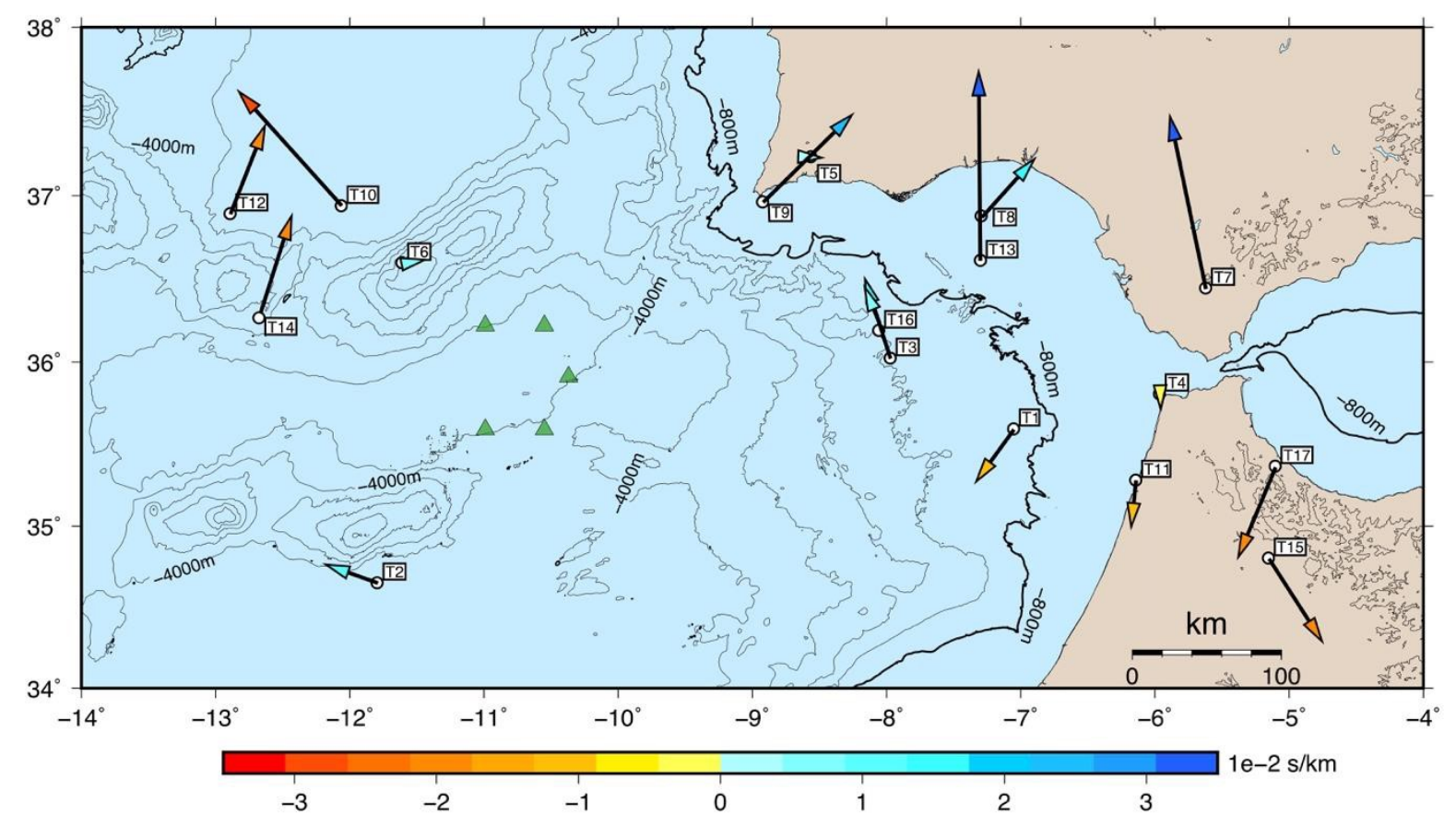

Figure 13. Slowness deviation. Arrows point from E2 to E1 locations and the head arrow colors highlight the slowness difference (Sp Difference Table 1, difference between theoretical slowness from ray tracing using the Earth velocity 3D model and estimated slowness from the CWT methodology of the P-wave). The length of the arrows is proportional to the slowness deviation (i.e., see color scale). The bathymetry isoline at $800 \mathrm{~m}$ depth is highlighted. 
Table 1. Results from the slowness vector estimation and the array epicenter determination. E1, hypocenter estimation from the seismic network. E2, epicenter estimation from the array. Dist Center Array corresponds to the distance from the array reference to E2. L1 is the length of the minor error ellipse axis and $\mathrm{L} 2$ is the major error ellipse axis of $\mathrm{E} 1 . B A Z_{P, S}$ is the back azimuth derived from the slowness vector. $B A Z_{P, S}$ Difference is the difference between the back azimuth of the great circle arc (from the array reference to E1) and the back azimuth that is derived from the slowness vector. $S_{P}$ Difference is the difference between the empirical slowness and the slowness that is derived from the slowness vector. $\left|S_{P, S}\right|$, is the slowness absolute value. $\triangle B A Z$ and $\Delta S$ are the errors associated with the back azimuth and the slowness when the maximum power decreases by $5 \%$.

\begin{tabular}{|c|c|c|c|c|c|c|c|c|c|c|c|c|c|c|}
\hline & To & $\begin{array}{c}\text { RMS } \\
(\mathrm{s})\end{array}$ & $\begin{array}{l}\text { Magnitude } \\
\text { (mbLg) }\end{array}$ & E1 & E2 & $\begin{array}{l}\text { Depth } \\
(\mathrm{km})\end{array}$ & $\begin{array}{c}\text { Dist } \\
\text { Center } \\
\text { Array } \\
\end{array}$ & $\begin{array}{c}\mathrm{L} 1 \\
(\mathrm{~km})\end{array}$ & $\begin{array}{c}\mathrm{L} 2 \\
(\mathrm{~km})\end{array}$ & $\begin{array}{c}\text { Dist } \\
|\mathrm{E} 1-\mathrm{E} 2| \\
(\mathrm{km}) \\
\end{array}$ & $\begin{array}{c}B A Z_{P, S} \\
\text { Difference } \\
\text { (o) }\end{array}$ & $\begin{array}{c}B A Z_{P, S} \\
\pm \triangle B A Z \\
\text { (o) }\end{array}$ & $\begin{array}{c}S_{P, S} \\
\text { Difference } \\
(\mathrm{s} / \mathrm{km}) \\
\end{array}$ & $\begin{array}{c}\left|S_{P, S}\right| \\
\pm \Delta S_{P, S} \\
(\mathrm{~s} / \mathrm{km})\end{array}$ \\
\hline $\mathrm{T} 1$ & $\begin{array}{l}17-09-2015 \\
15: 11: 45.02\end{array}$ & 0.41 & 5.0 & $\begin{array}{l}35.71 \\
-7.03\end{array}$ & $\begin{array}{l}35.59 \\
-7.05\end{array}$ & $36 \pm 8$ & 332 & 1 & 2 & 13.1 & $\begin{array}{l}4 \\
7\end{array}$ & $\begin{array}{c}97 \pm 1 \\
100 \pm 1\end{array}$ & -0.012 & $\begin{array}{l}0.11 \pm 0.01 \\
0.22 \pm 0.02\end{array}$ \\
\hline $\mathrm{T} 2$ & $\begin{array}{c}28-09-2015 \\
07: 25: 9.13\end{array}$ & 0.48 & 4.5 & $\begin{array}{r}34.70 \\
-11.87\end{array}$ & $\begin{array}{r}34.65 \\
-11.79\end{array}$ & $58 \pm 2$ & 172 & 5 & 9 & 9.5 & $\begin{array}{c}-4 \\
0\end{array}$ & $\begin{array}{c}215 \pm 2 \\
218 \pm 3\end{array}$ & 0.011 & $\begin{array}{l}0.13 \pm 0.01 \\
0.21 \pm 0.01\end{array}$ \\
\hline T3 & $\begin{array}{l}28-09-2015 \\
17: 03: 40.24\end{array}$ & 0.26 & 2.3 & $\begin{array}{l}36.14 \\
-7.963\end{array}$ & $\begin{array}{l}36.02 \\
-7.97\end{array}$ & $48 \pm 15$ & 248 & 2 & 3 & 13.3 & $\begin{array}{l}3 \\
8\end{array}$ & $\begin{array}{l}86 \pm 4 \\
92 \pm 4\end{array}$ & 0.016 & $\begin{array}{l}0.12 \pm 0.03 \\
0.21 \pm 0.04\end{array}$ \\
\hline $\mathrm{T} 4$ & $\begin{array}{l}20-10-2015 \\
20: 15: 25.44\end{array}$ & 0.30 & 4.7 & $\begin{array}{l}35.81 \\
-5.73\end{array}$ & $\begin{array}{l}35.81 \\
-5.96\end{array}$ & $27 \pm 9$ & 449 & 2 & 4 & 21.0 & $\begin{array}{c}0 \\
10\end{array}$ & $\begin{array}{c}91 \pm 2 \\
100 \pm 2\end{array}$ & -0.003 & $\begin{array}{l}0.12 \pm 0.02 \\
0.19 \pm 0.02\end{array}$ \\
\hline T5 & $\begin{array}{l}21-10-205 \\
8: 39: 58.80\end{array}$ & 0.63 & 3.0 & $\begin{array}{l}37.23 \\
-8.54\end{array}$ & $\begin{array}{r}37.23 \\
-8.56\end{array}$ & $22 \pm 1$ & 243 & 1 & 2 & 2.0 & $\begin{array}{l}-1 \\
-4\end{array}$ & $\begin{array}{l}51 \pm 2 \\
49 \pm 2\end{array}$ & 0.002 & $\begin{array}{l}0.12 \pm 0.02 \\
0.20 \pm 0.02\end{array}$ \\
\hline T6 & $\begin{array}{l}24-10-2015 \\
20: 31: 17.00\end{array}$ & 0.27 & 2.4 & $\begin{array}{c}36.53 \\
-11.54\end{array}$ & $\begin{array}{r}36.59 \\
-11.61\end{array}$ & $43 \pm 10$ & 103 & 3 & 4 & 10.0 & $\begin{array}{c}2 \\
-3.2\end{array}$ & $\begin{array}{l}314 \pm 3 \\
309 \pm 2\end{array}$ & 0.005 & $\begin{array}{l}0.12 \pm 0.02 \\
0.21 \pm 0.02\end{array}$ \\
\hline $\mathrm{T} 7$ & $\begin{array}{l}07-11-2015 \\
18: 11: 58.27\end{array}$ & 0.41 & 4.0 & $\begin{array}{l}36.68 \\
-5.47\end{array}$ & $\begin{array}{l}36.44 \\
-5.62\end{array}$ & $18 \pm 15$ & 472 & 2 & 3 & 14.5 & $\begin{array}{l}6 \\
3\end{array}$ & $\begin{array}{l}84 \pm 2 \\
81 \pm 2\end{array}$ & 0.032 & $\begin{array}{l}0.12 \pm 0.01 \\
0.19 \pm 0.02\end{array}$ \\
\hline T8 & $\begin{array}{l}18-11-2015 \\
13: 13: 15.24\end{array}$ & 0.23 & 3.0 & $\begin{array}{l}36.80 \\
-7.17\end{array}$ & $\begin{array}{l}36.87 \\
-7.29\end{array}$ & $31 \pm 3$ & 332 & 1 & 2 & 13.7 & $\begin{array}{c}-3 \\
5\end{array}$ & $\begin{array}{l}69 \pm 2 \\
77 \pm 2\end{array}$ & 0.014 & $\begin{array}{l}0.11 \pm 0.02 \\
0.19 \pm 0.02\end{array}$ \\
\hline T9 & $\begin{array}{l}\text { 19-11-2015 } \\
21: 57: 02.71\end{array}$ & 0.29 & 3.2 & $\begin{array}{l}36.90 \\
-8.92\end{array}$ & $\begin{array}{l}36.96 \\
-8.92\end{array}$ & $37 \pm 2$ & 187 & 1 & 2 & 11.4 & $\begin{array}{c}-2 \\
4\end{array}$ & $\begin{array}{l}53 \pm 2 \\
60 \pm 1\end{array}$ & 0.024 & $\begin{array}{l}0.12 \pm 0.01 \\
0.19 \pm 0.01\end{array}$ \\
\hline T10 & $\begin{array}{l}01-12-2015 \\
11: 09: 59.89\end{array}$ & 0.31 & 4.5 & $\begin{array}{r}36.95 \\
-12.08\end{array}$ & $\begin{array}{r}36.94 \\
-12.06\end{array}$ & $58 \pm 11$ & 171 & 3 & 12 & 2.7 & $\begin{array}{c}0 \\
-3\end{array}$ & $\begin{array}{l}312 \pm 2 \\
310 \pm 2\end{array}$ & -0.028 & $\begin{array}{l}0.11 \pm 0.01 \\
0.22 \pm 0.02\end{array}$ \\
\hline T11 & $\begin{array}{l}06-12-2015 \\
22: 17: 42.06\end{array}$ & 0.27 & 3.5 & $\begin{array}{l}35.34 \\
-6.17\end{array}$ & $\begin{array}{l}35.28 \\
-6.14\end{array}$ & $0.5 \pm 14$ & 414 & 2 & 10 & 7.9 & $\begin{array}{l}1 \\
8\end{array}$ & $\begin{array}{c}98 \pm 3 \\
106 \pm 3\end{array}$ & -0.009 & $\begin{array}{l}0.12 \pm 0.01 \\
0.18 \pm 0.02\end{array}$ \\
\hline T12 & $\begin{array}{l}\text { 21-12-2015 } \\
02: 17: 04.81\end{array}$ & 0.28 & 4.2 & $\begin{array}{r}36.80 \\
-13.18\end{array}$ & $\begin{array}{c}36.89 \\
- \\
12.89\end{array}$ & $58 \pm 13$ & 244 & 5 & 11 & 28.0 & $\begin{array}{c}7 \\
-9\end{array}$ & $\begin{array}{l}301 \pm 2 \\
285 \pm 2\end{array}$ & -0.017 & $\begin{array}{l}0.10 \pm 0.01 \\
0.21 \pm 0.01\end{array}$ \\
\hline T13 & $\begin{array}{l}31-12-2015 \\
20: 04: 39.78\end{array}$ & 0.20 & 2.9 & $\begin{array}{l}36.55 \\
-7.26\end{array}$ & $\begin{array}{l}36.61 \\
-7.40\end{array}$ & $15 \pm 2$ & 317 & 1 & 2 & 14.4 & $\begin{array}{l}4 \\
6\end{array}$ & $\begin{array}{l}80 \pm 2 \\
82 \pm 2\end{array}$ & 0.034 & $\begin{array}{l}0.12 \pm 0.02 \\
0.20 \pm 0.02\end{array}$ \\
\hline T14 & $\begin{array}{l}09-01-2016 \\
06: 25: 30.09\end{array}$ & 0.15 & 4.7 & $\begin{array}{r}36.15 \\
-12.69\end{array}$ & $\begin{array}{r}36.19 \\
-12.67\end{array}$ & $48 \pm 17$ & 182 & 4 & 13 & 12.6 & $\begin{array}{l}5 \\
1\end{array}$ & $\begin{array}{l}284 \pm 2 \\
279 \pm 2\end{array}$ & -0.019 & $\begin{array}{l}0.10 \pm 0.02 \\
0.20 \pm 0.02\end{array}$ \\
\hline T15 & $\begin{array}{l}25-02-2016 \\
01: 03: 24.02\end{array}$ & 0.65 & 2.8 & $\begin{array}{r}34.89 \\
-5.18\end{array}$ & $\begin{array}{l}34.80 \\
-5.15\end{array}$ & $2 \pm 2$ & 513 & 3 & 5 & 10.5 & $\begin{array}{c}-3 \\
7\end{array}$ & $\begin{array}{c}98 \pm 2 \\
108+2\end{array}$ & -0.018 & $\begin{array}{l}0.13 \pm 0.02 \\
0.21 \pm 0.02\end{array}$ \\
\hline T16 & $\begin{array}{l}02-03-2016 \\
13: 41: 11.68\end{array}$ & 0.27 & 4.0 & $\begin{array}{l}36.22 \\
-8.16\end{array}$ & $\begin{array}{l}36.23 \\
-8.05\end{array}$ & $45 \pm 10$ & 231 & 2 & 3 & 10.3 & $\begin{array}{l}2 \\
6\end{array}$ & $\begin{array}{l}83 \pm 2 \\
87 \pm 2\end{array}$ & 0.007 & $\begin{array}{l}0.12 \pm 0.02 \\
0.20 \pm 0.02\end{array}$ \\
\hline T17 & $\begin{array}{l}07-03-2016 \\
12: 33: 18.98\end{array}$ & 0.26 & 3.9 & $\begin{array}{l}35.50 \\
-5.11\end{array}$ & $\begin{array}{l}35.36 \\
-5.10\end{array}$ & $15 \pm 18$ & 507 & 1 & 6 & 15.8 & $\begin{array}{l}4 \\
5\end{array}$ & $\begin{array}{l}97 \pm 4 \\
99 \pm 5\end{array}$ & -0.018 & $\begin{array}{l}0.11 \pm 0.03 \\
0.20 \pm 0.04\end{array}$ \\
\hline
\end{tabular}




\section{References}

Allen, R., 1982. Automatic phase pickers: Their present use and future prospects. Bulletin of the Seismological Society of America 72, S225-S242.

Almendros, J., Ibáñez, J.M., Alguacil, G., Del Pezzo, E., 1999. Array analysis using circularwave-front geometry: an application to locate the nearby seismo-volcanic source. Geophysical Journal International 136, 159-170.

Bayram, İ., 2013. An analytic wavelet transform with a flexible time-frequency covering. IEEE Transactions on Signal Processing 61, 1131-1142.

Bear, L.K., Pavlis, G.L., 1997. Estimation of slowness vectors and their uncertainties using multi-wavelet seismic array processing. Bulletin of the Seismological Society of America 87, 755-769.

Behr, Y., Townend, J., Bowen, M., Carter, L., Gorman, R., Brooks, L., Bannister, S., 2013. Source directionality of ambient seismic noise inferred from three-component beamforming. Journal of Geophysical Research: Solid Earth 118, 240-248.

Beyreuther, M., Barsch, R., Krischer, L., Megies, T., Behr, Y., Wassermann, J., 2010. ObsPy: A Python toolbox for seismology. Seismological Research Letters 81, 530-533.

Bruns, A., 2004. Fourier-, Hilbert-and wavelet-based signal analysis: are they really different approaches? Journal of neuroscience methods 137, 321-332.

Capon, J., 1969. High-resolution frequency-wavenumber spectrum analysis. Proceedings of the IEEE 57, 1408-1418.

Carpenter, E., 1965. An historical review of seismometer array development. Proceedings of the IEEE 53, 1816-1821.

Cessaro, R.K., 1994. Sources of primary and secondary microseisms. Bulletin of the Seismological Society of America 84, 142-148.

Collins, J., Vernon, F., Orcutt, J., Stephen, R., 2002. Upper mantle structure beneath the Hawaiian swell: Constraints from the ocean seismic network pilot experiment. Geophysical research letters 29, 17-11-17-14.

Dahm, T., Krueger, F., Hannemann, K., 2013. Propagation characteristics of Po/So in the lithosphere of the Eastern Atlantic ocean revealed from automatic incoherent ocean bottom array processing, AGU Fall Meeting Abstracts.

Dahm, T., Tilmann, F., Morgan, J., 2006. Seismic broadband ocean-bottom data and noise observed with free-fall stations: Experiences from long-term deployments in the North Atlantic and the Tyrrhenian Sea. Bulletin of the Seismological Society of America 96, 647-664.

Daubechies, I., Bates, B.J., 1992. Ten lectures on wavelets. ASA.

Doornbos, D., 1974. Seismic wave scattering near caustics: Observations of PKKP precursors. Nature 247, 352-353.

Frankel, A., Hough, S., Friberg, P., Busby, R., 1991. Observations of Loma Prieta aftershocks from a dense array in Sunnyvale, California. Bulletin of the Seismological Society of America 81, 1900-1922.

Friedrich, A., Krueger, F., Klinge, K., 1998. Ocean-generated microseismic noise located with the Gräfenberg array. Journal of Seismology 2, 47-64.

Gal, M., Reading, A.M., Ellingsen, S., Gualtieri, L., Koper, K., Burlacu, R., Tkalčić, H., Hemer, M., 2015. The frequency dependence and locations of short-period microseisms generated in the Southern Ocean and West Pacific. Journal of Geophysical Research: Solid Earth 120, 57645781 . 
Gharti, H.N., Oye, V., Roth, M., Kühn, D., 2010. Automated microearthquake location using envelope stacking and robust global optimizationAutomated microearthquake location. Geophysics 75, MA27-MA46.

Gibbons, S.J., 2012. The Applicability of Incoherent Array Processing to IMS Seismic Arrays. Pure and Applied Geophysics 171, 377-394.

Gibbons, S.J., Ringdal, F., 2012. Seismic monitoring of the North Korea nuclear test site using a multichannel correlation detector. IEEE transactions on geoscience and remote sensing 50, 1897-1909.

Gibbons, S.J., Ringdal, F., Kværna, T., 2008. Detection and characterization of seismic phases using continuous spectral estimation on incoherent and partially coherent arrays. Geophysical Journal International 172, 405-421.

Goldstein, P., Walter, W.R., Zandt, G., 1992. Upper mantle structure beneath central Eurasia using a source array of nuclear explosions and waveforms at regional distances. Journal of Geophysical Research: Solid Earth 97, 14097-14113.

González-Fernández, A., Córdoba, D., Matias, L., Torné, M., 2001. Seismic crustal structure in the Gulf of Cadiz (SW Iberian Peninsula). Marine Geophysical Researches 22, 207-223.

Grandin, R., Borges, J.F., Bezzeghoud, M., Caldeira, B., Carrilho, F., 2007. Simulations of strong ground motion in SW Iberia for the 1969 February $28(\mathrm{M} \mathrm{s}=8.0)$ and the 1755 November 1 (M 8.5) earthquakes-I. Velocity model. Geophysical Journal International 171, 1144-1161. Grevemeyer, I., Lange, D., Villinger, H., Custódio, S., Matias, L., 2017. Seismotectonics of the Horseshoe Abyssal Plain and Gorringe Bank, eastern Atlantic Ocean: Constraints from ocean bottom seismometer data. Journal of Geophysical Research: Solid Earth 122, 63-78.

Grigoli, F., Cesca, S., Vassallo, M., Dahm, T., 2013. Automated seismic event location by travel-time stacking: An application to mining induced seismicity. Seismological Research Letters 84, 666-677.

Grossmann, A., Kronland-Martinet, R., Morlet, J., 1989. Reading and understanding continuous wavelet transforms, Wavelets. Time-Frequency Methods and Phase Space. Springer, Berlin, Heidelberg, pp. 2-20.

Haney, M.M., Power, J., West, M., Michaels, P., 2012. Causal instrument corrections for shortperiod and broadband seismometers. Seismological Research Letters 83, 834-845.

Hannemann, K., Krüger, F., Dahm, T., 2013. Measuring of clock drift rates and static time offsets of ocean bottom stations by means of ambient noise. Geophysical Journal International 196, 1034-1042.

Ishii, M., Shearer, P.M., Houston, H., Vidale, J.E., 2005. Extent, duration and speed of the 2004 Sumatra-Andaman earthquake imaged by the Hi-Net array. Nature 435, 933.

Jiménez-Munt, I., Fernàndez, M., Torne, M., Bird, P., 2001. The transition from linear to diffuse plate boundary in the Azores-Gibraltar region: results from a thin-sheet model. Earth and Planetary Science Letters 192, 175-189.

Kao, H., Shan, S.J., 2007. Rapid identification of earthquake rupture plane using sourcescanning algorithm. Geophysical Journal International 168, 1011-1020.

Kennett, B., Furumura, T., 2013. High-frequency Po/So guided waves in the oceanic lithosphere: I-long-distance propagation. Geophysical Journal International 195, 1862-1877. Kim, W.Y., Richards, P.G., 2007. North Korean nuclear test: Seismic discrimination low yield. Eos, Transactions American Geophysical Union 88, 158-161.

Kito, T., Krüger, F., 2001. Heterogeneities in D" beneath the southwestern Pacific inferred from scattered and reflected P-waves. Geophysical research letters 28, 2545-2548.

Koper, K.D., Hutko, A.R., Lay, T., Ammon, C.J., Kanamori, H., 2011. Frequency-dependent rupture process of the $2011 \mathrm{M} \mathrm{w} 9.0$ Tohoku Earthquake: Comparison of short-period $\mathrm{P}$ wave backprojection images and broadband seismic rupture models. Earth, planets and space 63, 16. 
Krüger, F., Dahm, T., Hannemann, K., 2020. Mapping of Eastern North Atlantic Ocean seismicity from Po/So observations at a mid-aperture seismological broad-band deep sea array. Geophys. J. Int. 221, 1055-1080.

Krüger, F., Ohrnberger, M., 2005. Tracking the rupture of the $\mathrm{M} w=9.3$ Sumatra earthquake over 1,150 km at teleseismic distance. Nature 435, 937.

Krüger, F., Weber, M., Scherbaum, F., Schlittenhardt, J., 1993. Double beam analysis of anomalies in the core-mantle boundary region. Geophysical research letters 20, 1475-1478.

Kumar, P., Foufoula-Georgiou, E., 1997. Wavelet analysis for geophysical applications. Reviews of geophysics 35, 385-412.

Kværna, T., Ringdal, F., 2013. Detection capability of the seismic network of the International Monitoring System for the Comprehensive Nuclear-Test-Ban Treaty. Bulletin of the Seismological Society of America 103, 759-772.

Le, B.M., Yang, T., Chen, Y.J., Yao, H., 2018. Correction of OBS clock errors using Scholte waves retrieved from cross-correlating hydrophone recordings. Geophysical Journal International 212, 891-899.

Lomax, A., Michelini, A., Curtis, A., 2009. Earthquake location, direct, global-search methods. Encyclopedia of complexity and systems science, 2449-2473.

Lomax, A., Zollo, A., Capuano, P., Virieux, J., 2001. Precise, absolute earthquake location under Somma-Vesuvius volcano using a new three-dimensional velocity model. Geophysical Journal International 146, 313-331.

Mallat, S., 2009. A wavelet tour of signal processing, Third ed. Academic Press.

Mallick, S., Frazer, L., 1990. Po/So synthetics for a variety of oceanic models and their implications for the structure of the oceanic lithosphere. Geophysical Journal International 100, 235-253.

Nawab, S., Dowla, F., Lacoss, R., 1985. Direction determination of wideband signals. IEEE transactions on acoustics, speech, and signal processing 33, 1114-1122.

Oppenheim, A.V., Schafer, R.W., 2010. Discrete-time signal processing, 3rd ed. Pearson, Upper Saddle River.

Palano, M., González, P.J., Fernández, J., 2015. The Diffuse Plate boundary of Nubia and Iberia in the Western Mediterranean: Crustal deformation evidence for viscous coupling and fragmented lithosphere. Earth and Planetary Science Letters 430, 439-447.

Reading, A.M., Koper, K.D., Gal, M., Graham, L.S., Tkalčić, H., Hemer, M.A., 2014. Dominant seismic noise sources in the Southern Ocean and West Pacific, 2000-2012, recorded at the Warramunga Seismic Array, Australia. Geophysical research letters 41, 3455-3463.

Ringdal, F., Husebye, E., Dahle, A., Beauchamp, K., 1975. P-wave envelope representation in event detection using array data. Nordhoff-Leiden, The Netherlands, pp. 353-372.

Rioul, O., Flandrin, P., 1992. Time-scale energy distributions: A general class extending wavelet transforms. IEEE Trans. Signal Process. 40, 1746-1757.

Rost, S., Thomas, C., 2002. Array seismology: Methods and applications. Reviews of geophysics 40, 2-1-2-27.

Rost, S., Thomas, C., 2009. Improving Seismic Resolution Through Array Processing Techniques. Surveys in Geophysics 30, 271-299.

Ruigrok, E., Gibbons, S., Wapenaar, K., 2017. Cross-correlation beamforming. Journal of Seismology 21, 495-508.

Scherbaum, F., 2001. Of poles and zeros: Fundamentals of digital seismology. Springer Science \& Business Media.

Schweitzer, J., Fyen, J., Mykkeltveit, S., Kvaerna, T., 2002. Seismic arrays: in new manual of seismological observatory practice-NMSOP. IASPEI, 481-532. 
Selby, N.D., 2010. Relative locations of the October 2006 and May 2009 DPRK announced nuclear tests using international monitoring system seismometer arrays. Bulletin of the Seismological Society of America 100, 1779-1784.

Shiobara, H., Nakanishi, A., Shimamura, H., Mjelde, R., Kanazawa, T., Berg, E.W., 1997. Precise positioning of ocean bottom seismometer by using acoustic transponder and CTD. Marine Geophysical Researches 19, 199-209.

Shito, A., Suetsugu, D., Furumura, T., Sugioka, H., Ito, A., 2013. Small-scale heterogeneities in the oceanic lithosphere inferred from guided waves. Geophysical research letters 40, 17081712.

Stachnik, J., Sheehan, A.F., Zietlow, D., Yang, Z., Collins, J., Ferris, A., 2012. Determination of New Zealand ocean bottom seismometer orientation via Rayleigh-wave polarization. Seismological Research Letters 83, 704-713.

Stähler, S.C., Sigloch, K., Hosseini, K., Crawford, W.C., Barruol, G., Schmidt-Aursch, M., Tsekhmistrenko, M., Scholz, J.-R., Mazzullo, A., Deen, M., 2016. Preliminary performance report of the RHUM-RUM ocean bottom seismometer network around La Réunion, western Indian Ocean. Advances in Geosciences 41, 43-63.

Tilmann, F.J., Dahm, T., 2008. Constraints on crustal and mantle structure of the oceanic plate south of Iceland from ocean bottom recorded Rayleigh waves. Tectonophysics 447, 66-79.

Torne, M., Fernàndez, M., Vergés, J., Ayala, C., Salas, M.C., Jimenez-Munt, I., Buffett, G.G., Díaz, J., 2015. Crust and mantle lithospheric structure of the Iberian Peninsula deduced from potential field modeling and thermal analysis. Tectonophysics 663, 419-433.

Trnkoczy, A., 1999. Topic Understanding and parameter setting of STA/LTA trigger algorithm. New manual of seismological observatory practice 2.

Weber, M., Davis, J., Thomas, C., Krüger, F., Scherbaum, F., Schlittenhardt, J., Körnig, M., 1996. The structure of the lowermost mantle as determined from using seismic arrays. Seismic modeling of the Earth's structure, 399-442.

Wessel, P., Smith, W.H., Scharroo, R., Luis, J., Wobbe, F., 2013. Generic mapping tools: improved version released. Eos, Transactions American Geophysical Union 94, 409-410.

Zha, Y., Webb, S.C., Menke, W., 2013. Determining the orientations of ocean bottom seismometers using ambient noise correlation. Geophysical Research Letters 40, 3585-3590.

Zitellini, N., Gràcia, E., Matias, L., Terrinha, P., Abreu, M., DeAlteriis, G., Henriet, J., Dañobeitia, J., Masson, D., Mulder, T., 2009. The quest for the Africa-Eurasia plate boundary west of the Strait of Gibraltar. Earth and Planetary Science Letters 280, 13-50. 